Article

\title{
Analysis of Difference in Household Debt across Regions of Thailand
}

\author{
Paravee Maneejuk $^{1}$, Sopanid Teerachai ${ }^{2}$, Atinuch Ratchakit ${ }^{2}$ and Woraphon Yamaka ${ }^{1, * \mathbb{D}}$ \\ 1 Center of Excellence in Econometrics, Faculty of Economics, Chiang Mai University, \\ Chiang Mai 50200, Thailand; paravee.m@cmu.ac.th \\ 2 Faculty of Economics, Chiang Mai University, Chiang Mai 50200, Thailand; sopanid_t@cmu.ac.th (S.T.); \\ atinuch_r@cmu.ac.th (A.R.) \\ * Correspondence: woraphon.yamaka@cmu.ac.th
}

Citation: Maneejuk, P.; Teerachai, S.; Ratchakit, A.; Yamaka, W. Analysis of Difference in Household Debt across Regions of Thailand. Sustainability 2021, 13, 12253. https://doi.org/ $10.3390 /$ su132112253

Academic Editors: Marek Durica, Lucia Svabova, Jaroslav Frnda and Katarina Kramarova

Received: 13 October 2021

Accepted: 3 November 2021

Published: 6 November 2021

Publisher's Note: MDPI stays neutral with regard to jurisdictional claims in published maps and institutional affiliations.

Copyright: (c) 2021 by the authors. Licensee MDPI, Basel, Switzerland. This article is an open access article distributed under the terms and conditions of the Creative Commons Attribution (CC BY) license (https:/ / creativecommons.org/licenses/by/ $4.0 /)$.

\begin{abstract}
This study analyzed the determinants of household debt in Thailand at both the regional and the national levels using the panel data of 76 provinces over the years 2009-2017. The Panel Quantile Regression Model was employed to enable the analysis of the formation of household debt ranging from low to high levels. The findings indicate that household indebtedness in different regions has been shaped by a variety of factors, and that households in the same region with different levels of debt burden would experience different impacts or outcomes. We also tested the convergence of household debt, which produced the thought-provoking finding that household debt convergence failed to occur at both the national and the regional levels, while household debt divergence was found instead at the statistical significance level in some regions. The growing debt divergence phenomenon might be an outcome indicator of the unequal access to credit sources among different households in Thai society.
\end{abstract}

Keywords: debt convergence; household debt; inequality; panel quantile regression; Thailand

\section{Introduction}

In Thailand, the household is an economic unit vital in driving the country's economy, because of its functioning simultaneously as both the owner of production inputs and the consumer. However, Thailand at present is facing the problem of a substantial rise in household debt. In practice, household borrowing is like a double-edged sword, because its use can be favorable and/or dangerous for the country's development. Borrowing can render positive effects on the economy if the borrower has adequate skills and knowledge to make use of the borrowed funds for productive investment and future income earning; on the contrary, it can harm the economy if the loan is used solely for enhancing consumption spending [1,2]. Furthermore, households that have heavy debt burden for a lengthy time, or have a high debt-to-income ratio, might become unable to repay the loans, causing the national problem of non-performing loans that subsequently adversely affect the stability of the financial systems and future national economic development.

Considering the household debt statistics of Thai people classified by the borrowing objectives over the 2004-2017 period, Thai borrowers used loans primarily for consumption purposes, followed by housing. The predominance of consumption loans reflects the high proportion of household debt in the personal loan, credit card, and auto loan sectors, which are considered as short-term loans for the use of future income for current consumption. Although borrowing for consumption can increase consumption and help enhance GDP, its positively contributary effect may be transient. Furthermore, future household consumption may be reduced when a part of the future household income must be used for loan repayment and other costs and obligations; and the reduced disposable income may lead to repeated borrowing and perpetual indebtedness. Moreover, a report on Thai household debt situation in 2018 revealed the total outstanding household debt 
in the first quarter of 2018 to be 12.17 trillion baht, which is a $5.2 \%$ increase from the level in 2017, and at a rate comparable with the incessant growth of small loans given by the commercial banks.

The statistics shown above suggest that household debt in Thailand has remained a serious problem that must be solved, because the tendencies of continuingly rising levels of outstanding household debts, and the growth rate of household debt being higher than that of the economy, could become the factors restraining spending, investment, and sustainable economic development in the future. Besides, a high debt level can be harmful to human quality of life, and cause some people to fall into the debt trap, especially those in the lowand middle-income groups that have relatively limited loan repayment ability and are more vulnerable to adverse economic shocks compared to other groups in society. There is also a high chance that the wide and persistent outstanding debts could subject the economy to the problem of non-performing loans.

As stated earlier, it is crucial for Thailand to maintain indebtedness at a manageable level, and to be able to control the level of household debt; thus, it becomes imperative to examine the factors behind household debt formation in Thailand. Consequently, this study was conducted to analyze Thai household debt by addressing three main subjects. (1) Analysis of Thai household debt at the national and regional levels using the Panel Quantile Regression method proposed by Koenker [3]. The model not only takes into account the differences in social and demographic characteristics across different provinces, but also embraces the quantile concept to enable the detection of the varying influences of each debt-formation determinant on households in different indebtedness groups, ranging from low to high levels in each province. In essence, this model was employed assuming that the effects of the factors influencing household debt may exhibit variations in magnitude and sign in different quantiles. (2) Regional study of whether the determinants of household debts have equal effects on all households in each quantile. This is necessary because each household debt determinant may have unequal effects on households in different quantiles. For example, the number of married households may have a different influence in different quantiles, perhaps because households in the lower quantile are more efficient at financial planning. (3) Testing debt convergence. This is to determine whether the household debt-creation behaviors in all quantiles in each region and at the overall level have a tendency to become similar and converge.

To the best of our knowledge, there have been few studies on debt convergence [4-6], and debt convergence across the Thai provinces is still not explored. Therefore, we contribute to the literature by investigating the debt-convergence hypothesis at the regional and the national levels. If the debt-convergence hypothesis holds in the case of Thailand, then the findings from this study may be supportive for policy decisions by the Bank of Thailand in setting measures to effectively solve the household debt problem. We strongly believe that households in different groups of indebtedness levels in different geographic regions of Thailand have different reasons behind their borrowing, and that the difference in household debt situations exists not only at the regional level but also in comparison with the national level, and this has persisted for a long time. Thus, it can be concluded that the presence of household debt divergence is a meaningful explanation for, as well as a reflection of, the inadequacy of the state's policies to solve household income disparity and debt problems. In addition, although the determinants of household debt in Thailand have already been studied (see, [7-10]), the inconclusive results were obtained when samples, models, and variables used for analysis were different. We also argue that the main shortcoming of the literature is that the results may be biased due to the neglect of distributional heterogeneity. Thus, we contribute to the literature by investigating the heterogenous effects of factors affecting household debt on both regional and national levels.

This study is divided into five main sections. Section 1 presents the background and significance of the household debt problem in Thailand. Section 2 reviews the related literature. Section 3 describes the methodology, models, data, and variables used in this study. Section 4 presents the study findings, and conclusions and policy recommendations 
are provided in Section 5.

\section{Literature Review}

The determinants of household debt have been the focus of several studies. This study conducted a literature review of the relevant studies and research works for presentation of the major issues.

\subsection{Household Debt Determinant Studies in Thailand}

Despite the rapid rise of household debt in Thailand during this decade, it is rare to find studies on Thai household debt determinants. As one purpose of this study is to investigate the determinants of Thai household debt, only papers concerning the factors affecting debt in Thailand are reviewed in this sub-section. Amornlerdphanich et al. [7] investigated the determinants of household debt burdens in Northern Thailand using the probit and linear regression models, taking the socio-economic characteristics and debt-generation behavior of households as key factors. They concluded that marital status, education, age of household head, household income, and household asset value could determine the household debt burden. Lerskullawa [10], using the national-level data, investigated factors affecting household debt in Thailand, and concluded that social factors, including education, marriage, and young population, and economic factors, including household income, inflation rate, and household consumption expenditure play an important role in total household debt. Similarly, Chotewattanakul, Sharpe and Chand [11] suggested that high household income and household savings could reduce the probability of being over-indebted, while a higher level of dependency on finance can lead to a higher probability of being over-indebted.

In a study by Ho and Mainal [12] on the determinants of household indebtedness in five ASEAN countries including Malaysia, Singapore, Thailand, the Philippines, and Indonesia, it was found that the interest rate has a significant effect on household debt in Thailand. In a parallel attempt, Chichaibelu and Waibel [9] analyzed the determinants of household over-indebtedness and its persistence for rural household borrowers in Thailand and Vietnam, using the Heckman random effects dynamic probit model, in which the household demographic, socioeconomic, and behavioral characteristics were considered possible factors affecting household debt in these two countries. They showed that household characteristics including poverty, household size, education, and income are significantly related to the household indebtedness in both nations.

\subsection{Socio-Demographic Determinants of Household Debt}

Difference in socio-demographic characteristics has been regarded as a reason behind the varying levels of household debt in various areas, and has been a subject of investigation in several research works. For example, Amornlerdphanich et al. [7] examined the debt-creation behavior of households in Northern Thailand and the determinants of debt creation, and found that the education, marital status, economic class, age of the household head, and the number of dependent members of household are the factors affecting household debt-creation decisions at the statistical significance level. Their findings are consistent with the study results of Rangsipaht et al. [8], which revealed that personal factors, particularly education level, strongly influence household debt creation, and the higher the education level, the lower the household debt level. Education level has been found to be an important factor determining household debt in other countries as well. For example, a study by Kotze [13] on factors affecting the financial behaviors of people in South Africa found that the rising household debt level is attributable to lack of discipline in financial management of the household, poor financial literacy, and the use of the disposable income almost entirely for consumption, leaving only a small portion of the income for savings and investment.

Another important factor affecting household debt is household income. Previous studies on Thailand revealed that low-income households are likely to fall into heavy 
indebtedness. For example, Muthitacharoen, Nuntramas and Chotewattanakul [14] concluded from their investigation that a decrease in income level can lead to increased borrowing that is generally for consumption purposes. Similarly, Lerskullawat [10] found that there exists a negative relationship between household income and household debt. However, research works on the household income and debt nexus in other countries have produced contrasting findings, such as the study by Baker [15] in the USA that indicated that American households tend to have larger household debt as their income rises, probably because they can access loan sources more conveniently and easily than people in the low-income group. This finding is consistent with the earlier conclusion of Keese [16], who examined household indebtedness in Germany, that household income and indebtedness level are positively related.

Meanwhile, some research works considered other crucial factors, such as registered marriage, the number of family members, and household income, age and risk perception. Lea, Webley, and Walker [17] and Wildauer [18] revealed that registered marriage and the number of family members contribute a positive impact to household debt in the USA. The results from these studies are in line with Lerskullawat [10] in Thailand. Crawford and Faruqui [19] found that higher household income and age led to larger household debt in Canada. In addition, Rahman et al. [20] confirmed that risk perception had a highly significant effect on the indebtedness of Malaysian people.

\subsection{Economic Determinants of Household Debt}

The effect of macroeconomic situations on Thai household debt has previously been examined, leading to the finding that household debt creation increases at a higher rate during economic recession than in the periods of normality. At the international level, Son and Park [21] investigated the impact of U.S. interest rates on household debt sustainability in Korea, and found that interest-rate vulnerable households were sensitive to gradual changes in interest rates. Mian, Sufi and Verner [22] conducted a study on the relationship between household debt levels and the world economic cycle, and found the economic changes have a direct impact on household debt, but the impact varied across countries and the phases of the economic cycle. Their findings are consistent with the study results of Muthitacharoen, Nuntramas and Chotewattanakul [14], which revealed households, particularly those in the low-income category, to be more likely to borrow during the economic downturn compared to normal economic times. Likewise, Debelle $[1,2]$ also investigated the macroeconomic impact on household debt, and found that households in low-income countries tend to increase household borrowing in times of economic recession to maintain current consumption levels, and that the additional borrowing is short-term in nature, simply to augment household financial capacity. Thus, it can be concluded that economic growth and household indebtedness have an inverse relationship.

However, Meniago et al. [23] studied the causes of household debt in South Africa and found household debt to be significantly affected by positive changes in gross domestic product and household consumption. This result also corresponded to Meng, Hoang and Siriwardana [24], who explored the determinants of Australian household debt. Meanwhile, Abd Samad, Daud and Dali [25] conducted a study in emerging economies, and highlighted that financial development, house prices and lending interest rate have mainly been associated with rising household debt, while the unemployment rate and inflation are negatively associated with household debt.

As mentioned above, various determinants of household debt are found in the literature, where many empirical results reveal a significant effect of variables of interest, while some fail to confirm the significance of these variables. Moreover, the determinant variables may exhibit different magnitude and sign of the effects on household debt. Several reasons may explain the considerable differences in conclusions. Zhu et al. [26] revealed that inconclusive results can be obtained when samples, models, and variables used for analysis are different. However, this study argues that the main shortcoming of the literature is that the results may be biased due to the neglect of distributional heterogeneity. Thus, 
this paper examines the determinants of household debt in Thailand considering distributional heterogeneity in the panel quantile regression framework. Moreover, although the determinants of household debt in Thailand have already been studied to a great extent [7-10], none of the previous studies produced results that comprehensively reflect the actual household debt situation. This is because the studies were conducted either at the aggregate level or for a specific area, resulting in findings that were not strong enough to provide policy recommendations to effectively solve the household debt problem in each geographic region. In reality, Thai people in one region are different from those in others in many aspects, such as income level, primary occupation, lifestyle, and social values; and, thus, the extent and purpose of household borrowing are likely to differ across regions. Furthermore, a financial policy report of Bank of Thailand in 2018 revealed that although the household debt-to-income ratio in Thailand decreased, household borrowing was concentrated only in some regions of the country. Therefore, study at the regional level may be able to reveal more thoroughly than at the countrywide level the differences in the causes and nature of household borrowing and indebtedness across geographic areas. Besides, in the same region or area, there can be differences between the urban and rural sectors regarding household debt issues and household debt-to-income ratio. Meanwhile, households in different indebtedness quantiles can be affected dissimilarly by the same external welfare shock.

From the perspective of methodology, most of these previous studies utilized the linear regression model to investigate the determinants of household debt. However, due to the great diversity of behavior and characteristics, household debt may exhibit a pattern of heterogeneity [27]. Therefore, it necessary to further observe whether the determinants change depending on distribution. Specifically, the determinant variables may exhibit variations in magnitude and sign depending on the household debt quantile. Therefore, this study analyzed the determinants of household debt in Thailand using the panel quantile regression model. It is expected that the obtained results could be very useful for solving any level of household debt in Thailand. To the best of our knowledge, this is the first attempt at using the panel quantile regression model to analyze the determinants of household debt for different levels of household debt in Thailand.

Moreover, a regional approach was taken in this study to compare the influence of each household debt determinant in different regions with the expectation that the findings on the similar or different effects of each determinant across regions would be useful information for the government and the Bank of Thailand to devise and implement appropriate policies for solving household debt problems across the board.

\section{Research Methodology}

\subsection{Data and Variables Description}

This study utilized the panel data of 76 provinces in Thailand over the period 2009-2018. The choice of the variables for this investigation was made upon the availability of data. Based on the previous studies, in this study, the annual average household debt was used as a dependent variable, while sociodemographic characteristics, economic characteristics and credit-accessibility characteristics were considered as factors affecting household debt. Sociodemographic characteristics considered were the number of years of education received by people aged 15-59, the number of registered marriages, household expenditure, and household income $[16,18]$. The second group of independent variables was related to economic characteristics, namely, employment rate, proportion of population living in poverty, and gross provincial product per capita [10,23-25]. Lastly, this study contributes to the determinants of household debt literature by providing novel evidence on the effects of credit-accessibility development for household financing. Thus, the number of branches of commercial banks was used to present credit-accessibility characteristics. Despite the existence of several studies attempting to understand the factors determining the household debt, surprisingly little is known about the impact of credit accessibility on household financing. 
All the variables were transformed into natural logarithms to reduce the problem of heteroscedasticity and obtain the stationarity. The description of each variable is provided in Table 1.

Table 1. Variable description.

\begin{tabular}{ccc}
\hline Variable & Variable Definition & Source \\
\hline DEBT & Household debt (baht per household) & $\begin{array}{c}\text { Office of the National Economic and } \\
\text { Social Development Council }\end{array}$ \\
\hline EDU & $\begin{array}{c}\text { Number of years of education received } \\
\text { by people aged between 15-59 (years) }\end{array}$ & $\begin{array}{c}\text { Office of the National Economic and } \\
\text { Social Development Council }\end{array}$ \\
\hline EMPL & $\begin{array}{c}\text { Proportion of the active population } \\
\text { employed (percentage) }\end{array}$ & $\begin{array}{c}\text { Office of the National Economic and } \\
\text { Social Development Council }\end{array}$ \\
\hline EXP & $\begin{array}{c}\text { Household expenditure (baht per } \\
\text { household) }\end{array}$ & $\begin{array}{c}\text { Office of the National Economic and } \\
\text { Social Development Council }\end{array}$ \\
\hline INC & household income (baht per household) & $\begin{array}{c}\text { Office of the National Economic and } \\
\text { Social Development Council }\end{array}$ \\
\hline POORINC & $\begin{array}{c}\text { Proportion of population living in } \\
\text { poverty (percentage) }\end{array}$ & $\begin{array}{c}\text { Office of the National Economic and } \\
\text { Social Development Council }\end{array}$ \\
\hline MAR & $\begin{array}{c}\text { Number of registered marriage } \\
\text { (thousand registered marriage) }\end{array}$ & National Statistical Office of Thailand \\
\hline GPP & $\begin{array}{c}\text { Gross provincial product per capita } \\
\text { (baht) }\end{array}$ & National Statistical Office of Thailand \\
\hline BRA & $\begin{array}{r}\text { Number of branches of commercial } \\
\text { banks (branch) }\end{array}$ & Bank of Thailand \\
\hline
\end{tabular}

\subsection{Methodology}

In this study, the 76 provinces were considered at two levels: the national and the regional, or groups designated as the North, Central, Northeast, South, East, and West. Then, an investigation was conducted into the determinants of household debt in each group of provinces at given quantile levels, using the panel quantile regression model. Next, the equality of the obtained quantile regression coefficients was tested to verify whether the differences along the estimated coefficients were significant across quantiles. Finally, debt convergence was examined for each region using Beta-convergence and Sigma-convergence.

\subsubsection{Panel Quantile Regression Model}

This study considered the difference in social and demographic characteristics across different provinces and their impacts on different household debt levels (ranging from low to high debt levels in each province). This study, thus, conducted a panel quantile regression, (PQR) as proposed by Koenker [28], to investigate heterogeneous effects of social and demographic determinants on household debt in 76 provinces in Thailand from 2009 to 2017, such that the determinants of household debt could be examined through conditional distribution, especially in provinces with high and low household debt levels.

The conditional quantile function of the dependent variable of individual $i$ at time $t, y_{i t}$, given the $k \times 1$ vector of the independent variables of individual $i$ at time $t, X_{i t}$, is expressed as follows

$$
Q_{y_{i t}}\left(\tau \mid X_{i t}\right)=\alpha_{i}+X_{i t}^{\prime} \beta(\tau), \quad i=1, \ldots, N, t=1, \ldots, T,
$$

where $Q_{y_{i t}}(\cdot)$ is the quantile function of $y_{i t}$ conditional on $X_{i t}, \beta(\tau)$ is the $k \times 1$ vector of quantile regression coefficients at given quantile $\tau$, and $\alpha_{i}$ represents the individual effect of individual $i$. Note that $\alpha_{i}$ has a pure location shift effect on the conditional quantiles 
of the dependent variable, thus, only the effects of independent variables are allowed to depend upon the quantile $\tau$ of interest, while $\alpha_{i}$ does not.

To estimate this model, the present study considers the fixed effect estimation method proposed by Koenker [28]. The estimate of the quantile regression coefficient $\beta(\tau)$ is the solution to the following minimization problem.

$$
\hat{\beta}(\tau)_{F E}=\min _{\beta(\tau)} \sum_{k=1}^{K} \sum_{i=1}^{N} \sum_{t=1}^{T} w_{k} \rho\left(\tau_{k}\right)\left(y_{i t}-\alpha_{i}-X_{i t}^{\prime} \beta\left(\tau_{k}\right)\right),
$$

where $\rho(\tau)\left(u_{i t}\right)=\tau \max \left(u_{i t}, 0\right)+(1-\tau) \max \left(-u_{i t}, 0\right)$ is the quantile loss function. $w_{k}$ is the weight given to the $k$ th quantile, which controls for the contribution of the $k$ th quantile on the estimation of the individual effect $\alpha_{i}$. In this study, the equally weighted quantile $w_{k}=1 / K[29]$ is employed.

As this study aims to investigate the determinants of household debt for different levels of household debt in Thailand, the following estimation model is proposed:

$$
\begin{aligned}
\ln D E B T_{i t} & =\beta_{1}(\tau) \ln B R A_{i t}+\beta_{2}(\tau) \ln E D U_{i t}+\beta_{3}(\tau) E M P L_{i t}+\beta_{4}(\tau) \ln E X P_{i t} \\
& +\beta_{5}(\tau) \ln G D P_{i t}+\beta_{6}(\tau) \ln I N C_{i t}+\beta_{7}(\tau) \ln M A R_{i t}+\beta_{8}(\tau) \ln P O O R I N C_{i t}+\varepsilon_{i t},
\end{aligned}
$$

where the province is indexed by $i$ and time by $t$, and $\varepsilon_{i t}$ is the error term.

For the analysis at both the national and the regional levels, the empirical model (Equation (3)) is used for all groups. Moreover, the determinant variables may exhibit variation in magnitude and sign depending on the household debt quantile, whether the 10 th, 20th, 30th, 40th, 50th, 60th, 70th, 80th, or 90th quantile. To have a better economic interpretation, this study classified the 10th, 20th, and 30th quantiles as the low household debt regime, the 40th, 50th and 60th quantiles as the medium household debt regime, and the 70th, 80th and 90th quantiles as the high household debt regime.

\subsubsection{Testing the Equality of Quantile Regression Coefficients}

Testing whether the slopes of quantile coefficients, $\beta(\tau)$, for $\tau \in(0,1)$ are equal was meant to verify whether the differences among the estimated coefficients were significant across quantiles. This study used the Wald-test of Koenker and Bassett [30] to check for quantile coefficient equality across quantiles. As the households in this study were divided into three categories according to quantile levels, namely, the low household debt regime, the medium household debt regime, and the high household debt regime, the differences among the three regimes were examined as follows:

(1) Examining whether the coefficient of the low household debt regime, herein represented by the 0.20 th quantile, was the same as that in the medium household debt regime (the 50th quantile).

$$
\begin{aligned}
& \mathrm{H}_{0}: \hat{\beta}\left(\tau_{1}=0.2\right)=\hat{\beta}\left(\tau_{2}=0.5\right) \\
& \mathrm{H}_{1}: \hat{\beta}\left(\tau_{1}=0.2\right) \neq \hat{\beta}\left(\tau_{2}=0.5\right)
\end{aligned}
$$

(2) Examining whether the coefficient of the medium household debt regime, herein represented by the 0.50 th quantile, was the same as that in the high household debt regime (the 80 th quantile).

$$
\begin{aligned}
& \mathrm{H}_{0}: \hat{\beta}\left(\tau_{1}=0.5\right)=\hat{\beta}\left(\tau_{2}=0.8\right) \\
& \mathrm{H}_{1}: \hat{\beta}\left(\tau_{1}=0.5\right) \neq \hat{\beta}\left(\tau_{2}=0.8\right)
\end{aligned}
$$

(3) Examining whether the coefficient of the low household debt regime, herein represented by the 0.20 th quantile, was the same as that in the high household debt regime (the 80th quantile).

$$
\mathrm{H}_{0}: \hat{\beta}\left(\tau_{1}=0.2\right)=\hat{\beta}\left(\tau_{2}=0.8\right)
$$




$$
\mathrm{H}_{1}: \hat{\beta}\left(\tau_{1}=0.2\right) \neq \hat{\beta}\left(\tau_{2}=0.8\right)
$$

Then, the Wald-test can be defined as

$$
\text { Wald }- \text { test }=\frac{\hat{\beta}\left(\tau_{1}\right)-\hat{\beta}_{2}\left(\tau_{2}\right)}{\sqrt{V\left(\hat{\beta}\left(\tau_{1}\right)-\hat{\beta}\left(\tau_{2}\right)\right)}},
$$

where $V\left(\hat{\beta}\left(\tau_{1}\right)-\hat{\beta}\left(\tau_{2}\right)\right)$ or the variance-covariance matrices of the corresponding coefficients are obtained from the bootstrap procedure. Under $\mathrm{H}_{0}$, the Wald test statistic asymptotically follows a $\chi^{2}$ distribution with $q$ degrees of freedom.

\subsubsection{Testing Beta and Sigma Convergence}

As the debt level is presumed to spread unevenly across the Thai provinces, it was of interest to perform the convergence analysis of household debt among Thai provinces during 2008-2017. Again, the 76 provincial panel data were used in terms of six regions and the whole country to examine whether there debt convergence existed at the regional and the national levels. To achieve this purpose, the absolute or unconditional Beta convergence and Sigma convergence were considered. It is important to note that Beta convergence focused on detecting the possible catching-up debt process, while Sigma convergence simply referred to a reduction in disparities among the provinces through time. These two concepts were closely related. Formally, Beta-convergence was necessary but not sufficient for Sigma-convergence [31,32].

\section{Unconditional Beta-Convergence}

Beta-convergence was first introduced by Baumol [33], and then extended by Barro and Sala-i-Martin [34] and Mankiw et al. [35] to examine the convergence of economic growth. In this study, this approach was applied to examine whether the debt of the poor provinces increased faster than that of the rich provinces, therefore becoming insurmountable [36].

To estimate the unconditional Beta-convergence for household debt, the natural logdebt of the $i$ th province can be approximated by

$$
\ln \left(\frac{D E B T_{i, 2017}}{D E B T_{i, 2008}}\right)=\alpha+\beta \ln \left(n D E B T_{i, 2008}\right)+\mu_{i}
$$

where $\ln \left(\ln D E B T_{i, 2017} / \ln D E B T_{i, 2008}\right)$ is the growth of household debt of province $i$ for the period from 2008 to $2017, \alpha$ is the intercept term and $\beta$ is the estimated speed with which debts converge to their steady-state (Beta-convergence), and $\mu_{i}$ is the error term [32]. If $\beta<0$, this implies that there exists the debt convergence.

\section{Sigma-Convergence}

The other type of convergence conducted in this study was the Sigma-convergence which emerged only if there were declines in the dispersion of debt levels across provinces over time. In other words, Sigma-convergence simply referred to a reduction in disparities among provinces through time. In this test, the variance of household debt at time $t$ was computed as follows:

$$
\sigma_{t}^{2}=\frac{1}{N} \sum_{i=1}^{N}\left(D E B T_{i t}-\overline{D E B T_{t}}\right)^{2}
$$

where $\overline{D E B T_{t}}=\frac{1}{N} \sum_{i=1}^{N} D E B T_{i t}$ and $t=(2008,2017)$. If $\sigma_{2017}^{2}<\sigma_{2008}^{2}$, this implies the existence of the debt convergence.

\section{Empirical Results}

The findings from this study are presented in three subsections, including: (1) descriptive statistics of variables used in the study, (2) the panel unit root test results, 
and (3) the empirical results from the estimation of the effects of household debt determinants in different regions of Thailand, the test of the equality of quantile regression coefficients, and the test of household debt convergence.

\subsection{Descriptive Statistics}

The descriptive statistics of variables used in this study (in the logarithm form) are presented in Table 2. The positive and negative skewness values indicate that the random variables are distributed to both the left and the right sides of the mean, while the high kurtosis values suggest that the variables are distributed in concentration around the mean. The values of these two basic features of the data sets suggest that the variables probably have a non-normal distribution. Consequently, the Jarque-Bera (J-B) test was conducted to confirm whether the data were normally distributed, and the test revealed that virtually all variables in this study, except INC, had non-normal distribution. Thus, the Panel Quantile Regression (PQR) Model was considered suitable for application to our data sets, because the Quantile approach could help explain the behavior of a variable at different quantiles.

Table 2. Descriptive statistics of variables.

\begin{tabular}{cccccccccc}
\hline & BRA & DEBT & EDU & EMPL & EXP & GPP & INC & MAR & POORINC \\
\hline Mean & 0.904 & 5.082 & 0.948 & 1.849 & 4.193 & 4.985 & 4.293 & 3.465 & 1.032 \\
\hline Median & 0.903 & 5.106 & 0.944 & 1.851 & 4.193 & 4.933 & 4.291 & 3.434 & 1.123 \\
Maximum & 2.196 & 5.908 & 1.255 & 1.908 & 4.544 & 6.014 & 4.692 & 4.663 & 1.872 \\
Minimum & 0.000 & 3.762 & 0.826 & 1.748 & 3.729 & 4.460 & 3.860 & 2.825 & -1.097 \\
Std. Dev. & 0.305 & 0.226 & 0.046 & 0.023 & 0.125 & 0.308 & 0.135 & 0.309 & 0.467 \\
Skewness & 0.521 & -1.531 & 1.515 & -0.491 & -0.103 & 0.814 & 0.035 & 0.588 & -1.231 \\
Kurtosis & 5.219 & 9.181 & 9.550 & $4.042^{* * *}$ & 3.532 & 3.331 & 3.187 & 4.491 & 5.093 \\
J-B test & $95.16^{* * *}$ & $753.2^{* * *}$ & $824.7^{* * *}$ & $32.43^{* * *}$ & $5.14^{*}$ & $43.73^{* * *}$ & 0.634 & $57.1^{* * *}$ & $165.4^{* * *}$ \\
\hline
\end{tabular}

$* * *$ and ${ }^{*}$ indicate the statistical significance at the $1 \%$ and $10 \%$, respectively.

\subsection{Panel Unit Root Test Results}

Prior to being estimated by the panel quantile regression model, the panel time-series variables needed to be tested to determine whether they were non-stationary and whether they had a unit root. This study used four types of unit root test, including the Lin and $\mathrm{Chu}$, Hadri, Fisher-ADF, and Fisher-PP tests, of which the results are presented in Table 3. It can be seen that all the tests gave similar results and conclusions and that the time series were stationary at the statistically significant levels with constant mean and variance over time.

Table 3. Panel unit root test results.

\begin{tabular}{|c|c|c|c|c|c|c|c|c|c|}
\hline \multirow{2}{*}{ Unit Root Test } & \multicolumn{9}{|c|}{ Variable } \\
\hline & BRA & DEBT & EDU & EMPL & EXP & GPP & INC & MAR & POORINC \\
\hline LLC & $-167.1^{* * *}$ & $-12.2^{* * *}$ & $-9.8^{* * *}$ & $-5.8^{* * *}$ & $-10.8^{* * *}$ & $-12.2^{* * *}$ & $-19.6^{* * *}$ & $-31.5^{* * *}$ & $-5.4 *$ \\
\hline Fisher-ADF & 75.7 & $183.3^{* *}$ & 177.3 & 146.4 & 135.9 & 136.7 & $182.2^{* *}$ & $251.5^{* * *}$ & 110.6 \\
\hline Fisher-PP & 88.0 & $223.6^{* * *}$ & $205.7^{* * *}$ & 178.8 & $183.6^{* *}$ & $211.3^{* * *}$ & $241.2^{* * *}$ & $294.5^{* * *}$ & 143.5 \\
\hline Hadri & $16.8^{* * *}$ & $12.9^{* * *}$ & $11.4^{* * *}$ & $13.9^{* *}$ & $16.0^{* * *}$ & $17.1^{* * *}$ & $14.3^{* * *}$ & $12.9^{* * *}$ & $12.8^{* * *}$ \\
\hline
\end{tabular}

\subsection{Household Debt Analysis Results}

Household debt was analyzed based on the results of the panel quantile regression model estimation (Equation (5)) at both the regional level, covering six provincial groups, and the national level. The use of the quantile concept enabled the assignment of households with different debt quantiles to three regimes, namely the low household debt regime (10th, 20th, and 30th quantiles), the medium household debt regime (40th, 50th, 
and 60th quantiles), and the high household debt regime (70th, 80th, and 90th quantiles). The estimation results are presented in Tables 4-9.

\subsubsection{Thai Household Debt Analysis at the National Level}

The investigation of the determinants of household debt at the national level using the PQR model revealed that, at statistical significance levels, the factors of household expenditure (EXP), household income (INC), and gross provincial product (GPP) per capita have an influence on Thai household debt at all quantile levels, while the factors of the number of registered marriage (MAR) and the number of commercial bank branches (BRA) have an influence on the debt of those households falling in the low and the medium household debt regimes, but not the high household debt regime.

The PQR coefficients, as presented in Table 4, indicate that household expenditure is a factor causing household debt to vary in the same direction in all household debt regimes, with the strongest effect on households in the low household debt regime. To be precise, a $1 \%$ increase in household expenditure would lead to a rise in debt in households in the low household debt regime (10th, 20th, and 30th quantiles) by $0.682-1.491 \%$, while a rise in the medium and the high household debt regimes would lead to a debt rise in the range of $0.653-0.756 \%$ and $0.540-0.771 \%$, respectively. These findings mean an increase in household expenditure would cause households in all household debt quantiles to increase debt at statistical significance levels, with the strongest effect on households in the low household debt regime, as the estimated coefficients are in the range of 0.540-1.491. Meanwhile, the GPP per capita, which represents the effect of the macroeconomic factor, was found to be negatively associated with household debts at all quantile levels. This is because the rise in GPP per capita, which reflects the improved economic growth rate, can help reduce the level of household debt most significantly in households belonging to the low household debt regime, followed by the medium and the high household debt regimes, respectively. Furthermore, an increased number of registered marriages in a province would cause an increase in household debt level, particularly in the households in the low household debt regime.

Table 4. Coefficient estimates from the panel quantile regression model, the whole of Thailand.

\begin{tabular}{|c|c|c|c|c|c|c|c|c|c|}
\hline \multirow{3}{*}{ Determinant } & \multicolumn{9}{|c|}{ Quantile } \\
\hline & \multicolumn{3}{|c|}{ Low Debt Regime } & \multicolumn{3}{|c|}{ Medium Debt Regime } & \multicolumn{3}{|c|}{ High Debt Regime } \\
\hline & 10th & 20th & 30th & 40 th & 50 th & 60th & 70th & 80th & 90th \\
\hline \multirow{2}{*}{ Constant } & $-4.786^{* *}$ & -1.643 & 0.800 & 1.318 * & $1.703 *$ & 0.955 & 1.463 & $1.900 *$ & 1.405 \\
\hline & $(2.152)$ & (1.349) & $(1.112)$ & $(0.867)$ & $(0.957)$ & (1.049) & $(1.125)$ & (1.059) & (1.191) \\
\hline \multirow{2}{*}{ EXP } & $1.491^{* *}$ & $0.810 * *$ & $0.682 * * *$ & $0.677^{* * *}$ & $0.653^{* * *}$ & $0.756^{* * *}$ & $0.671^{* *}$ & 0.540 * & $0.771^{* * *}$ \\
\hline & $(0.542)$ & $(0.299)$ & $(0.242)$ & $(0.224)$ & $(0.235)$ & $(0.269)$ & $(0.327)$ & $(0.346)$ & $(0.269)$ \\
\hline \multirow{2}{*}{ MAR } & $0.467^{* * *}$ & $0.289^{* * *}$ & $0.165^{* *}$ & $0.158^{* * *}$ & $0.130 * *$ & $0.097^{*}$ & 0.085 & 0.026 & -0.024 \\
\hline & $(0.154)$ & $(0.076)$ & $(0.066)$ & $(0.056)$ & $(0.05)$ & $(0.047)$ & $(0.054)$ & $(0.05)$ & $(0.063)$ \\
\hline \multirow{2}{*}{ POORINC } & 0.079 & 0.048 & 0.012 & -0.010 & 0.014 & 0.041 & 0.029 & 0.011 & -0.010 \\
\hline & $(0.073)$ & $(0.054)$ & $(0.053)$ & $(0.04)$ & $(0.043)$ & $(0.042)$ & $(0.05)$ & $(0.050)$ & $(0.057)$ \\
\hline \multirow{2}{*}{ INC } & 0.421 & $0.741^{* *}$ & $0.709^{* * *}$ & $0.591^{* * *}$ & $0.514^{* *}$ & $0.490^{* *}$ & $0.524^{* *}$ & $0.579^{* *}$ & $0.535^{* *}$ \\
\hline & (0.524) & $(0.265)$ & (0.235) & (0.237) & (0.223) & (0.210) & $(0.262)$ & $(0.277)$ & $(0.241)$ \\
\hline \multirow{2}{*}{ GPP } & $-0.472^{* * *}$ & $-0.401^{* * *}$ & $-0.324^{* * *}$ & $-0.278^{* * *}$ & $-0.198^{* * *}$ & $-0.170 * * *$ & $-0.155^{* * *}$ & $-0.150^{* * *}$ & $-0.191 * * *$ \\
\hline & (0.091) & $(0.071)$ & (0.067) & $(0.056)$ & $(0.050)$ & (0.046) & $(0.045)$ & $(0.047)$ & $(0.048)$ \\
\hline \multirow{2}{*}{ EDU } & -0.109 & -0.046 & 0.027 & -0.007 & 0.034 & -0.078 & -0.280 & -0.316 & -0.436 \\
\hline & $(0.710)$ & $(0.375)$ & $(0.329)$ & $(0.234)$ & $(0.213)$ & $(0.219)$ & (0.199) & $(0.211)$ & $(0.288)$ \\
\hline \multirow[b]{2}{*}{ EMPL } & 1.440 & 0.653 & -0.288 & -0.352 & -0.524 & -0.257 & -0.329 & -0.265 & -0.118 \\
\hline & $(0.966)$ & $(0.375)$ & $(0.474)$ & $(0.331)$ & $(0.348)$ & $(0.352)$ & $(0.345)$ & $(0.413)$ & $(0.500)$ \\
\hline \multirow{2}{*}{ BRA } & $-0.340 * * *$ & $-0.203^{* *}$ & $-0.144 *$ & $-0.130 * *$ & $-0.097^{*}$ & -0.079 * & -0.045 & -0.007 & -0.002 \\
\hline & (0.100) & $(0.079)$ & $(0.072)$ & $(0.061)$ & $(0.057)$ & $(0.045)$ & $(0.046)$ & $(0.044)$ & $(0.050)$ \\
\hline
\end{tabular}

$* * * * * *$ indicate the statistical significance at the $1 \%, 5 \%$ and $10 \%$, respectively and the value in () is the standard error.

The coefficient estimates in Table 4 can also be presented graphically in Figure 1 to portray the change in the coefficient value of individual determinants along different quantile levels (10th-90th quantiles). In Figure 1, the black line shows the coefficients from the 10th to the 90th quantiles, and the dashed red line shows the average value of 
the impact of each determinant on household debt. It can be seen that the factors of EXP, MAR, and EMPL, which have a positive relationship with household debt, tend to lose their strength as the quantile (or household debt) level increases, and the factors of GPP and BRA, which have a negative effect on household debt, also lose their strength as the quantile level increases.

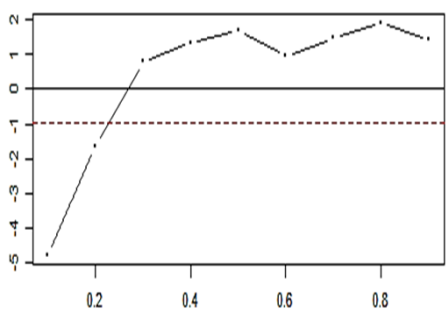

(a)

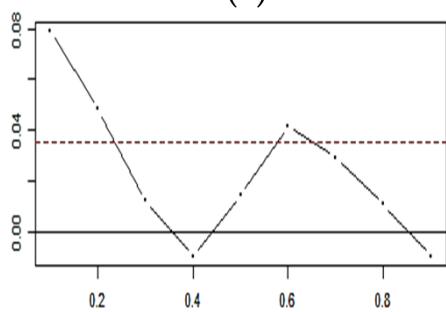

(d)

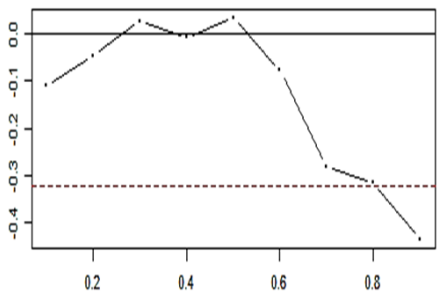

(g)

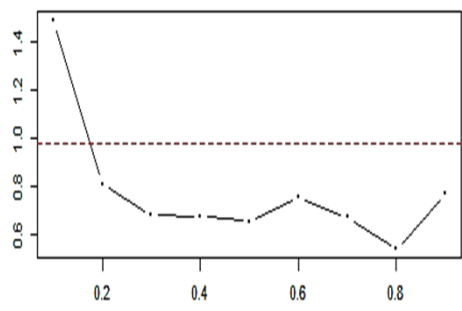

(b)

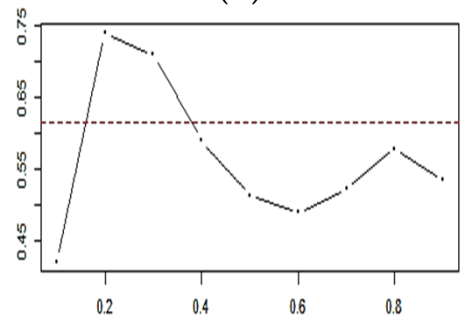

(e)

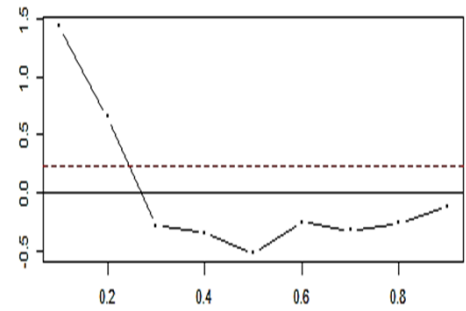

(h)

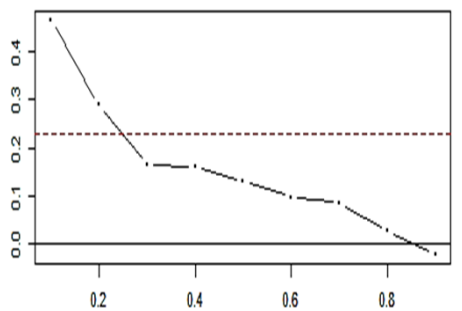

(c)

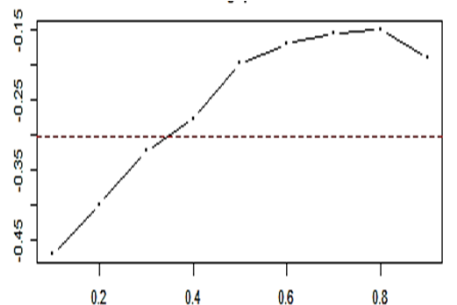

(f)

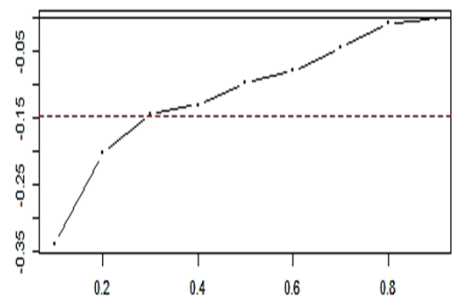

(i)

Figure 1. Coefficient values of each household debt determinant at different quantile levels (10th-90th), and whole country. (a) Constant. (b) EXP. (c) MAR. (d) POORINC. (e) INC (f) GPP. (g) EDU. (h) EMPL. (i) BRA.

\subsubsection{Household Debt Analysis for the Central Region}

Table 5 shows the factors determining household debt in the Central Region at the statistical significance level, including EXP, MAR, INC, GPP, and BRA. Household expenditure was found to have both positive and negative influences on household debt, depending on the quantile or the debt regime. Specifically, a 1\% increase in household expenditure corresponds to an increase in the debt level of households in the medium and the high household debt regimes by $0.818-1.321 \%$ and $0.736-1.499 \%$, respectively; but it will reduce the debt level by $0.760-1.569 \%$ for the households at the 10th and the 20th quantiles in the low debt regime. The latter relationship can arise if the households in the low debt regime recognize the need to lower their household debt when they have more household expenditure. However, a household able to prudently calculate the costs and benefits of a financial act probably has at least one member who is well-educated and has good financial discipline, and these qualifications are likely to be found mostly in people living in the Capital City or the Central Region of the country. A 1\% increase in the number of registered marriages will cause an increase in the debt level of households in the low and medium household debt regimes of $0.422-0.860 \%$ and $0.208-0.219 \%$, respectively. However, a $1 \%$ increase in MAR will slightly reduce the debt level of some households in the medium debt regime and all households in the high debt regime. While household income was found to have a positive association with debt level in all household debt regimes, the increased number of branches of commercial banks (BRA) was found to reduce household debt. 
A $1 \%$ increase in BRA results in a reduction in the debt level of households in the low and the medium household debt regimes of $0.387-0.777 \%$ and $0.081-0.159 \%$, respectively, a tendency very similar to the trends occurring on the national level. Thus, any policy formulated to tackle a problem at the national level will be beneficial and effective only for the geographic regions that closely match national averages.

Table 5. Coefficient estimates from the panel quantile regression model, Central Region.

\begin{tabular}{|c|c|c|c|c|c|c|c|c|c|}
\hline \multirow{3}{*}{ Determinant } & \multicolumn{9}{|c|}{ Quantile } \\
\hline & \multicolumn{3}{|c|}{ Low Debt Regime } & \multicolumn{3}{|c|}{ Medium Debt Regime } & \multicolumn{3}{|c|}{ High Debt Regime } \\
\hline & 10th & 20th & 30th & 40th & 50th & 60th & 70th & 80th & 90th \\
\hline \multirow{2}{*}{ Constant } & $9.207 * *$ & 8.366 & 5.438 & $3.648 *$ & $2.487 *$ & 3.242 & 1.996 & $3.392 *$ & 1.666 \\
\hline & $(6.301)$ & $(4.412)$ & (3.918) & $(3.757)$ & (3.483) & $(3.318)$ & $(3.322)$ & $(3.398)$ & (3.939) \\
\hline \multirow{2}{*}{ EXP } & $-1.569^{* *}$ & $-0.760 * *$ & $0.865 * * *$ & $1.052 * * *$ & $1.321 * * *$ & $0.818^{* * *}$ & $0.736 * *$ & 1.134 * & $1.499 * * *$ \\
\hline & $(2.105)$ & $(1.670)$ & $(1.330)$ & $(1.142)$ & $(0.934)$ & $(0.751)$ & $(0.652)$ & $(0.628)$ & $(0.932)$ \\
\hline \multirow{2}{*}{ MAR } & $0.860 * * *$ & $0.506^{* * *}$ & $0.422 * *$ & $0.219^{* * *}$ & $0.208 * *$ & $-0.084 *$ & -0.136 & -0.301 & -0.333 \\
\hline & $(0.317)$ & $(0.270)$ & $(0.276)$ & $(0.248)$ & $(0.235)$ & $(0.22)$ & $(0.184)$ & $(0.176)$ & $(0.21)$ \\
\hline \multirow{2}{*}{ POORINC } & -0.115 & -0.064 & -0.013 & -0.061 & -0.045 & -0.020 & -0.030 & -0.005 & -0.049 \\
\hline & $(0.206)$ & $(0.130)$ & $(0.132)$ & $(0.096)$ & $(0.095)$ & $(0.086)$ & $(0.079)$ & $(0.079)$ & $(0.087)$ \\
\hline \multirow{2}{*}{ INC } & 2.781 & $1.878^{* *}$ & $0.690 * * *$ & $0.493^{* * *}$ & $0.383 * *$ & $0.289 * *$ & $0.558 * *$ & $0.067 * *$ & $-0.172 * *$ \\
\hline & (1.457) & (1.352) & (1.119) & (1.080) & (0.862) & (0.649) & $(0.514)$ & $(0.51)$ & $(0.791)$ \\
\hline \multirow{2}{*}{ GPP } & $-0.407^{* * *}$ & $-0.281^{* * *}$ & $-0.382^{* * *}$ & $-0.428^{* * *}$ & $-0.491^{* * *}$ & $-0.313^{* * *}$ & $-0.277 * * *$ & $-0.252^{* * *}$ & $-0.217^{* * *}$ \\
\hline & $(0.257)$ & $(0.174)$ & $(0.144)$ & $(0.138)$ & (0.139) & $(0.138)$ & (0.127) & $(0.120)$ & (0.174) \\
\hline \multirow{2}{*}{ EDU } & -0.675 & -0.126 & -0.650 & -0.850 & -1.343 & -0.407 & -1.007 & -0.611 & -1.188 \\
\hline & $(2.01)$ & (1.134) & $(1.031)$ & $(0.869)$ & $(0.906)$ & $(0.814)$ & $(0.724)$ & $(0.704)$ & $(0.757)$ \\
\hline \multirow{2}{*}{ EMPL } & -4.994 & -4.344 & -3.016 & -1.458 & -0.761 & -0.336 & 0.230 & -0.299 & 0.670 \\
\hline & $(2.732)$ & (1.975) & $(1.943)$ & (1.928) & $(1.698)$ & $(1.584)$ & (1.569) & $(1.565)$ & $(1.956)$ \\
\hline \multirow{2}{*}{ BRA } & $-0.777^{* * *}$ & $-0.491^{* *}$ & -0.387 * & $-0.159^{* *}$ & -0.081 * & 0.160 * & 0.160 & 0.280 & 0.280 \\
\hline & $(0.327)$ & $(0.275)$ & $(0.268)$ & $(0.264)$ & $(0.243)$ & $(0.230)$ & $(0.184)$ & $(0.181)$ & $(0.216)$ \\
\hline
\end{tabular}

$* * * * *,{ }^{*}$ indicate the statistical significance at the $1 \%, 5 \%$ and $10 \%$, respectively and the value in () is the standard error.

The results in Table 5 can be graphically presented as in Figure 2 to show the varying impact of each determinant on household debt level in different quantiles, from low to high (10th-90th quantiles). Evidently, MAR, EDU, and EMPL have the tendency to lose more of their influence with growing household debt levels. In precise terms, these three factors, which affect household debt in the same direction for households in the low debt regime, do otherwise for households in the higher debt regime. Therefore, the government wishing to reduce household debt in the Central Region may need to encourage people to get married and increase employment, and provide education support for the local population. Surprisingly indeed, this finding suggests marriage can contribute to household debt reduction for households in the high debt regime in the Central Region of Thailand. It is considered that people who form a family unit are more likely to organize a systematic and careful financial management plan, including a goal to build up family wealth through savings, rather than getting into debt. On the contrary, EXP, POORINC, EMP, GPP, and BRA were found to have a greater influence when the household debt rises. From the study results, it can be concluded that household expenditure, proportion of population living in poverty, employment, macroeconomic situation, and the number of commercial bank branches are the crucial variables determining the high level of households borrowing of households in the Central Region of Thailand. It is interesting to note that the high degree of employment among people in the Central Region goes hand in hand with their high household debt level, and this might imply that the employed persons here have easier access to credit sources. 


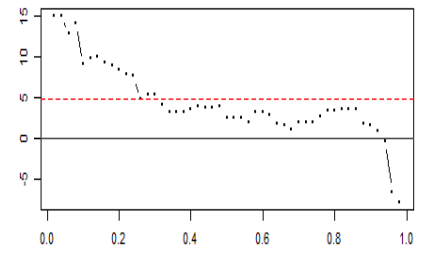

(a)

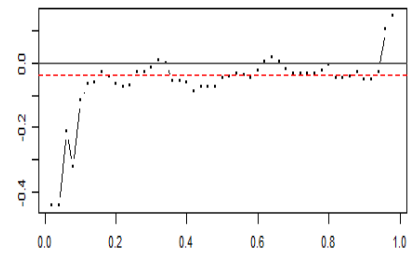

(d)

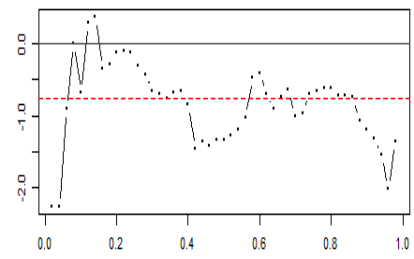

(g)

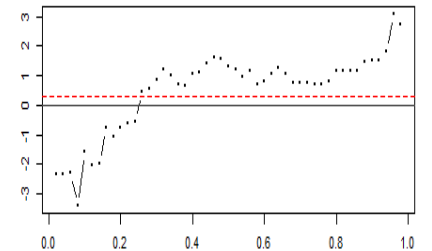

(b)

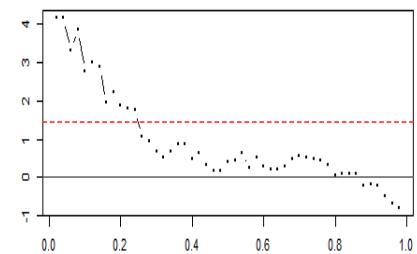

(e)

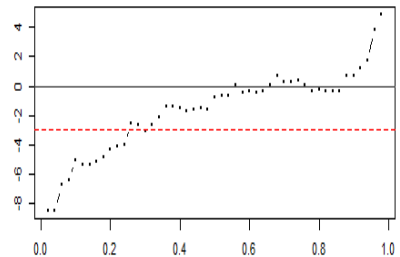

(h)

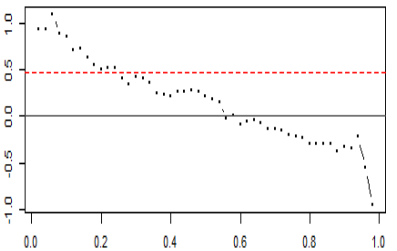

(c)

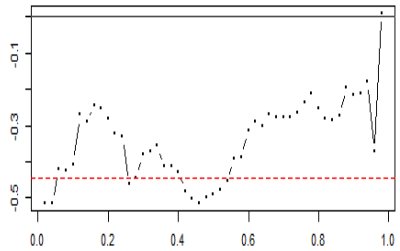

(f)

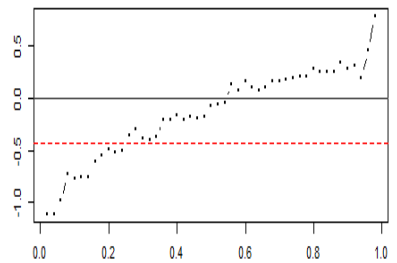

(i)

Figure 2. Coefficient values of each determinant of household debt at different quantile levels (10th-90th). Central Region. (a) Constant. (b) EXP. (c) MAR. (d) POORINC. (e) INC (f) GPP. (g) EDU. (h) EMPL. (i) BRA.

\subsubsection{Household Debt Analysis for the Northeastern Region}

The results presented in Table 6 reveal the statistically significant determinants of household debt in the Northeastern Region to include household expenditure and the number of registered marriages, which vary in the same direction. However, both variables have only a small effect wand only on some households in the medium and high debt regimes. The number of commercial bank branches was found to have a weak influence, with an inverse relation, on the debt of the households belonging to the medium household debt regime only. Meanwhile, household income exhibits a positive relationship with the household debt levels in all regimes, and is thus considered a fundamental factor influencing household borrowing in this region. A $1 \%$ increase in household income will result in an increase in household debt of $1.277-1.748 \%, 0.902-1.203 \%$, and $0.762-0.852 \%$ in the low, medium, and high household debt regimes, respectively. Intuitively, household debt should become smaller when household income gets higher for the households in the Northeast, where the number of low-income households is the highest in the country. Thus, the finding of a positive income-to-debt relationship may precisely manifest the fact that the poor have more difficulty obtaining formal loans due to their limited ability to provide collateral or guarantors acceptable to financial institutions; and once the poor can improve their income level, they are able to gain better access to lending sources and means of loan repayment, resulting in their higher level of household debt. Meanwhile, the proportion of the population living in poverty is a factor determining household debt with a positive relationship. A $1 \%$ increase in POORINC leads to an increase in household debt of $0.346-0.596 \%, 0.188-0.233 \%$, and $0.180-0.264 \%$ for households in the low, medium, and high debt regimes, respectively, in the Northeast. This finding lends support to the notion that low-income households are forced to borrow to finance their consumption and daily expenditure, which are beyond their existing means. Thus, in the Northeast, the high household debt level can be explained by the large proportion of the population living in poverty.

The results reported in Table 6 can be graphically presented as in Figure 3 to show the varying impact of each determinant on household debt at different quantile levels 
(10th-90th quantiles). It can be seen that MAR, POORINC, and INC tend to become less influential as the household debt rises. Conversely, EXP, EDU, EMP, and BRA become stronger in determining household debt at the higher levels. These results resemble the findings for other regions, except that the coefficient values of education indicate that people in the Northeast with higher educational attainment, surprisingly, have larger household debt, which is assumed to result from their borrowing for investment or housing purchase. Moreover, the GPP coefficient was found to be negative and fluctuating across quantiles, indicating that the expanding economy will contribute to a lighter household debt in households at all quantile levels, while the effects of macroeconomic factors on the high and the low debt regimes may not be much different.

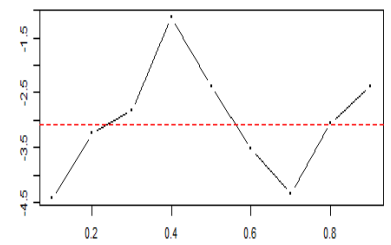

(a)

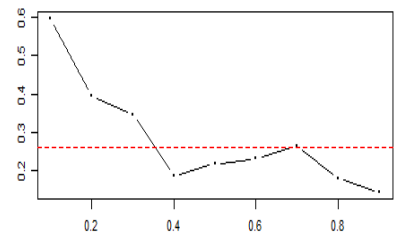

(d)

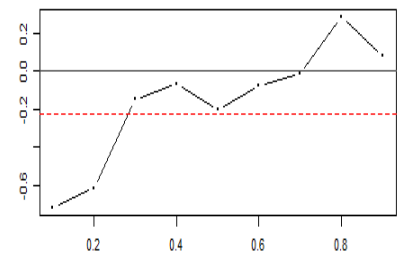

(g)

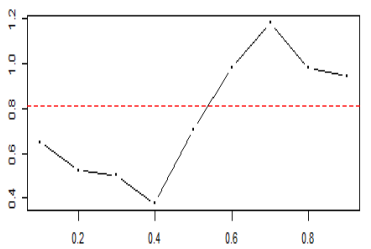

(b)

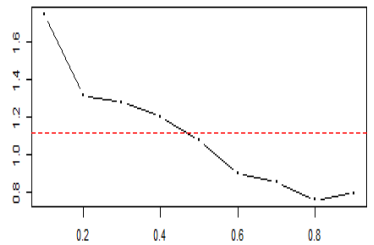

(e)

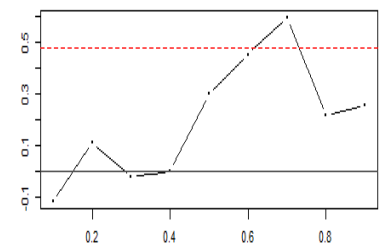

(h)

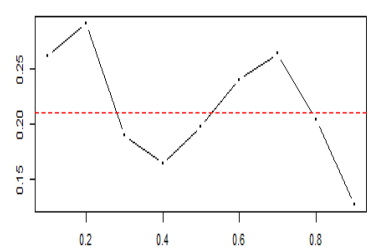

(c)

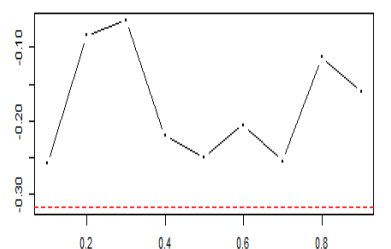

(f)

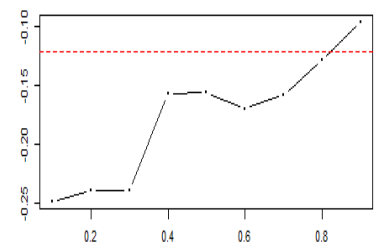

(i)

Figure 3. Coefficient values of each determinant of household debt at different quantile levels (10th-90th), Northeastern Region. (a) Constant. (b) EXP. (c) MAR. (d) POORINC. (e) INC (f) GPP. (g) EDU. (h) EMPL. (i) BRA.

Table 6. Coefficient estimates from the panel quantile regression model, Northeastern Region.

\begin{tabular}{|c|c|c|c|c|c|c|c|c|c|}
\hline \multirow{3}{*}{ Determinant } & \multicolumn{9}{|c|}{ Quantile } \\
\hline & \multicolumn{3}{|c|}{ Low Debt Regime } & \multicolumn{3}{|c|}{ Medium Debt Regime } & \multicolumn{3}{|c|}{ Low Debt Regime } \\
\hline & 10th & 20th & 10th & 40th & 10th & 60th & 10th & 80th & 90th \\
\hline \multirow{2}{*}{ Constant } & -4.427 & -3.249 & -2.825 & -1.122 & -2.380 & -3.532 & $-4.345^{* *}$ & -3.052 & -2.390 \\
\hline & $(3.847)$ & $(2.631)$ & $(2.678)$ & $(2.317)$ & $(2.372)$ & $(2.414)$ & $(2.020)$ & $(2.043)$ & $(2.754)$ \\
\hline \multirow[b]{2}{*}{ EXP } & 0.648 & 0.523 & 0.503 & 0.377 & 0.706 & $0.981 *$ & $1.180 * *$ & 0.977 & 0.939 \\
\hline & $(0.490)$ & $(0.441)$ & $(0.445)$ & $(0.458)$ & $(0.494)$ & $(0.56)$ & $(0.484)$ & $(0.485)$ & $(0.645)$ \\
\hline \multirow{2}{*}{ MAR } & 0.261 & $0.291 *$ & 0.189 & 0.164 & $0.197^{*}$ & $0.240^{* *}$ & $0.263 * *$ & 0.204 & 0.127 \\
\hline & $(0.177)$ & $(0.155)$ & $(0.137)$ & $(0.11)$ & $(0.110)$ & $(0.116)$ & $(0.123)$ & $(0.131)$ & $(0.177)$ \\
\hline \multirow{2}{*}{ POORINC } & $0.596^{* * *}$ & $0.394 * *$ & $0.346^{* *}$ & $0.188^{*}$ & $0.218^{* *}$ & $0.233 * *$ & $0.264^{* * *}$ & 0.180 * & 0.145 \\
\hline & $(0.156)$ & $(0.16)$ & $(0.133)$ & $(0.108)$ & $(0.105)$ & $(0.109)$ & $(0.091)$ & $(0.096)$ & $(0.11)$ \\
\hline \multirow{2}{*}{ INCOME } & $1.748^{* * *}$ & $1.317^{* * *}$ & $1.277^{* * *}$ & $1.203^{* * *}$ & $1.076^{* * *}$ & $0.902 * * *$ & $0.852 * *$ & $0.762 * *$ & 0.794 \\
\hline & $(0.328)$ & $(0.363)$ & $(0.330)$ & $(0.346)$ & $(0.316)$ & $(0.335)$ & $(0.353)$ & $(0.332)$ & (0.522) \\
\hline \multirow{2}{*}{ GPP } & -0.259 & -0.085 & -0.064 & -0.221 & -0.249 & -0.206 & -0.255 & -0.114 & -0.161 \\
\hline & $(0.206)$ & $(0.202)$ & $(0.241)$ & $(0.192)$ & $(0.201)$ & $(0.185)$ & (0.18) & $(0.238)$ & $(0.305)$ \\
\hline \multirow{2}{*}{ EDU } & -0.720 & -0.615 & -0.147 & -0.066 & -0.201 & -0.072 & -0.015 & 0.286 & 0.083 \\
\hline & $(0.969)$ & (1.001) & $(0.838)$ & $(0.775)$ & $(0.699)$ & $(0.658)$ & $(0.629)$ & $(0.625)$ & $(0.964)$ \\
\hline \multirow{2}{*}{ EMPL } & -0.117 & 0.114 & -0.022 & 0.000 & 0.300 & 0.454 & 0.597 & 0.217 & 0.258 \\
\hline & (1.351) & $(0.959)$ & $(0.841)$ & $(0.743)$ & $(0.712)$ & $(0.598)$ & $(0.533)$ & $(0.592)$ & (1.000) \\
\hline \multirow{2}{*}{ BRA } & -0.249 & -0.239 & -0.240 & -0.157 & -0.156 & -0.170 * & -0.158 & -0.129 & -0.096 \\
\hline & $(0.182)$ & $(0.165)$ & $(0.156)$ & $(0.13)$ & $(0.104)$ & $(0.098)$ & $(0.096)$ & $(0.096)$ & (0.114) \\
\hline
\end{tabular}

$* * * * *, *$ indicate the statistical significance at the $1 \%, 5 \%$ and $10 \%$, respectively and the value in () is the standard error. 


\subsubsection{Household Debt Analysis for the Eastern Region}

The results of household debt analysis for the Eastern Region shown in Table 7 indicate that among the statistically significant variables, the GPP inversely affects the borrowing of households in all quantile levels, and thus all household debt regimes, as in the case of the Central Region. In our view, economic expansion may cause household borrowing and debt to reduce across the board in the Central and the Eastern Regions, simply because of the economic significance of these two regions. EXP, or household expenditure, also affects household debt in the East in all household debt quantiles, but with a positive relationship. MAR influences the household debt of households in the low and the medium household debt regimes in the same direction, as a $1 \%$ increase in the number of registered marriages increases the borrowing of households in the low and the medium debt regimes by $0.086-0.206 \%$ and $0.104-0.143 \%$, respectively. Meanwhile, MAR was found not to be a statistically significant determinant of the borrowing by households in the high household debt regime. BRA, the number of branches of banks, was found to have a negative association with household debt in the low and medium household debt regimes, with the exception of households in the 20th quantile of the low debt regime, where a positive relationship exists. Similarly, household income generally affects household borrowing in the opposite direction, as a $\%$ increase in INCOME resulted in a reduction in household debt at statistically significant levels, in households in the low and medium debt regimes, of $0.323-0.414 \%$, and $0.109-0.261$, respectively. INCOME, however, was found to have both negative and positive effects on the borrowing of households in the high debt regime. In essence, the significant determinants of household debt in the East are nearly identical with those operating with quite similar effects in the Central Region and in the whole of Thailand.

Table 7. Coefficient estimates from the panel quantile regression model, Eastern Region.

\begin{tabular}{|c|c|c|c|c|c|c|c|c|c|}
\hline \multirow{3}{*}{ Determinant } & \multicolumn{9}{|c|}{ Quantile } \\
\hline & \multicolumn{3}{|c|}{ Low Debt Regime } & \multicolumn{3}{|c|}{ Medium Debt Regime } & \multicolumn{3}{|c|}{ Low Debt Regime } \\
\hline & 10th & 20th & 10th & 40th & 10th & 60th & 10th & 80th & 10th \\
\hline \multirow{2}{*}{ Constant } & $-5.369 * *$ & -2.499 & 1.090 & $1.382 *$ & $5.639 *$ & 4.842 & 5.073 & $2.457 *$ & -0.042 \\
\hline & $(6.821)$ & $(6.982)$ & $(6.309)$ & $(5.832)$ & $(5.479)$ & $(5.389)$ & $(5.425)$ & $(5.272)$ & $(5.872)$ \\
\hline \multirow{2}{*}{ EXP } & $0.611^{* *}$ & $0.887^{* *}$ & $0.754 * * *$ & $0.699 * * *$ & $0.848^{* * *}$ & $1.103^{* * *}$ & $0.728 * *$ & $1.246^{*}$ & $1.943^{* * *}$ \\
\hline & $(0.975)$ & $(1.105)$ & $(1.019)$ & $(1.064)$ & $(1.035)$ & $(1.124)$ & $(1.042)$ & $(1.168)$ & $(1.193)$ \\
\hline \multirow{2}{*}{ MAR } & $0.206^{* * *}$ & $0.086^{* * *}$ & $0.094 * *$ & $0.104^{* * *}$ & $0.141^{* *}$ & $0.143 *$ & 0.092 & 0.092 & 0.231 \\
\hline & $(0.309)$ & $(0.302)$ & $(0.269)$ & $(0.238)$ & $(0.218)$ & $(0.169)$ & $(0.171)$ & $(0.171)$ & $(0.222)$ \\
\hline \multirow{2}{*}{ POORINC } & -0.056 & -0.040 & -0.040 & -0.055 & -0.151 & -0.042 & -0.066 & 0.066 & 0.015 \\
\hline & $(0.125)$ & $(0.161)$ & $(0.134)$ & $(0.121)$ & $(0.154)$ & $(0.128)$ & $(0.145)$ & $(0.155)$ & $(0.16)$ \\
\hline \multirow{2}{*}{ INCOME } & -0.259 & $-0.414^{* *}$ & $-0.323^{* * *}$ & $-0.261^{* * *}$ & $-0.109 * *$ & $-0.191 * *$ & $0.087^{* *}$ & 0.074 ** & $-0.357^{* *}$ \\
\hline & (0.688) & (0.775) & $(0.684)$ & (0.795) & $(0.751)$ & $(0.744)$ & $(0.713)$ & (0.794) & $(0.866)$ \\
\hline \multirow{2}{*}{ GPP } & $-0.219^{* * *}$ & $-0.139^{* * *}$ & $-0.127^{* * *}$ & $-0.086^{* * *}$ & $-0.154^{* * *}$ & $-0.079 * * *$ & $-0.077^{* * *}$ & $-0.087^{* * *}$ & $-0.146^{* * *}$ \\
\hline & $(0.164)$ & (0.178) & $(0.169)$ & $(0.132)$ & (0.153) & $(0.123)$ & (0.148) & (0.147) & $(0.158)$ \\
\hline \multirow{2}{*}{ EDU } & -0.013 & -0.123 & 0.172 & -0.233 & -1.227 & -0.961 & -1.231 & -0.934 & -1.676 \\
\hline & (1.102) & $(1.491)$ & $(1.288)$ & $(1.271)$ & $(1.074)$ & $(1.056)$ & (1.136) & (1.127) & $(1.334)$ \\
\hline \multirow{2}{*}{ EMPL } & 5.080 & 3.291 & 1.322 & 1.253 & -1.012 & -1.374 & -1.098 & -1.031 & 0.142 \\
\hline & (3.024) & $(3.093)$ & $(2.973)$ & $(2.503)$ & $(2.242)$ & $(2.300)$ & $(2.014)$ & $(1.948)$ & $(2.202)$ \\
\hline \multirow{2}{*}{ BRA } & $-0.035^{* * *}$ & $0.035^{* *}$ & -0.072 * & $-0.127^{* *}$ & -0.164 * & $-0.143^{*}$ & -0.041 & 0.012 & -0.200 \\
\hline & $(0.348)$ & $(0.358)$ & $(0.347)$ & $(0.346)$ & $(0.297)$ & $(0.272)$ & $(0.269)$ & $(0.247)$ & $(0.323)$ \\
\hline
\end{tabular}

$* * *, * * *$ indicate the statistical significance at $1 \%, 5 \%$ and $10 \%$, respectively, and the value in () is the standard error.

The results shown in Table 7 can be presented graphically as in Figure 4 to help visualize the varying effects of each household debt determinant at different quantile levels (10th-90th quantiles). It is clear that, as household debt quantile level increases, EDU and EMP tend to lose their influence, while EXP becomes stronger. As for other determinants, their effects on household borrowing seem to be moderate for households in the low and high debt regimes, implying that the magnitude of their effects has a weak relationship with the household debt levels in the Eastern Region. 


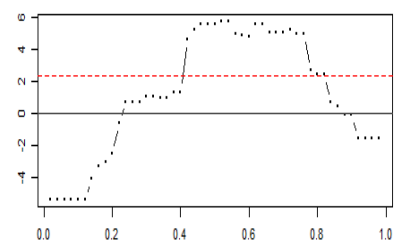

(a)

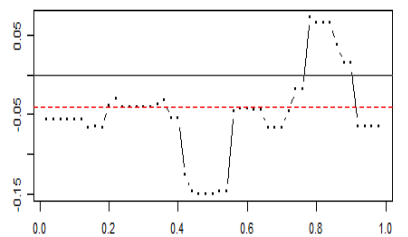

(d)

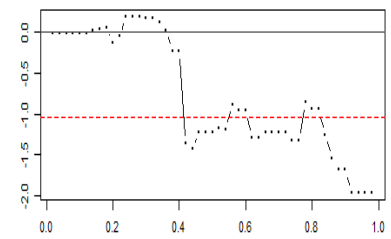

$(\mathrm{g})$

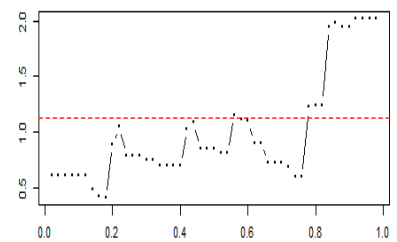

(b)

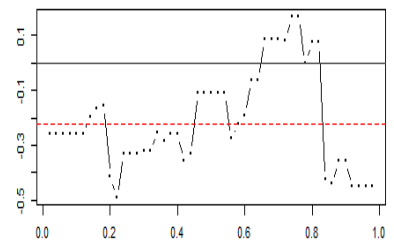

(e)

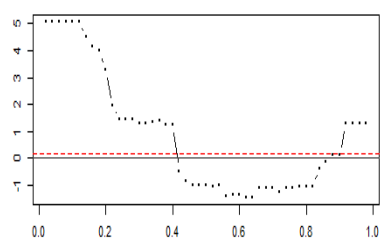

(h)

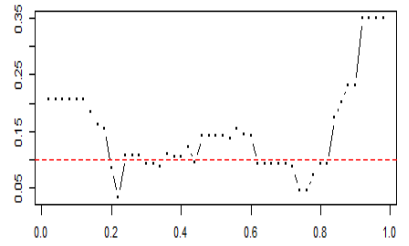

(c)

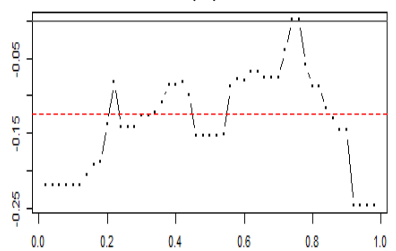

$(\mathbf{f})$

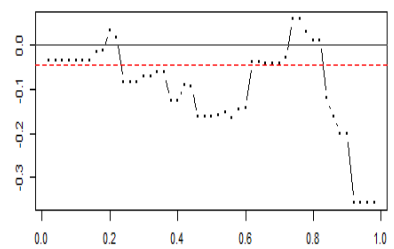

(i)

Figure 4. Coefficient values of each determinant of household debt at different quantile levels (10th-90th), Eastern Region. (a) Constant. (b) EXP. (c) MAR. (d) POORINC. (e) INC (f) GPP. (g) EDU. (h) EMPL. (i) BRA.

\subsubsection{Household Debt Analysis for the Northern Region}

As can be seen in Table 8, the statistically significant determinants of household debt in the North are EXP, MAR, POORINC, GPP, EMP, and BRA. Household expenditure affects household borrowing in the same direction in all households in the low and medium debt regimes, and some in the high debt regime. The number of registered marriages has a positive effect on households in the medium debt regime, and a negative effect on those in the low debt regime. The gross provincial product per capita, similarly to MAR, has a weak negative effect on households in the low debt regime. The proportion of the population living in poverty has an effect as hypothesized, primarily affecting the households in the medium household debt regime. Increased household debt is probably the consequence of a household having inadequate money to finance necessary expenditure, and household borrowing to finance the expenditure eventually causes the rise in household debt. Similarly to the Northeast, the North has a sizable number of lowincome households, and thus POORINC becomes the important determinant of household debt in this region. The proportion of the active population employed was found to inversely affect household debt, since a 1\% increase in EMPL will lead to a decrease in household debt of $-2.891,2.163 \%$ and $2.157 \%$ in households at the 2 nd, 3rd and 4 th quantiles in the low and the medium household debt regimes, respectively. Such an inverse relationship might arise because of attempts by households in the lower quantiles to allocate part of their additional income from increased employment to repay loans, thus causing the household debt level to decrease. It is worth observing that the distinct role of POORINC and EMPL in determining household debt in the North is something not noted in the research findings at the national level. The last statistically significant determinant in the North is the number of branches of the commercial banks, which, if it increases, helps reduce household debt. A $1 \%$ increase in BRA resulted in reductions in household debt of $0.473-0.553 \%$ and $0.409-0.550 \%$ in households in the low and the medium household debt regimes, respectively.

The findings reported in Table 8 can be presented in graphic form as in Figure 5 to show the varying effects of each determinant on household debt at different quantile 
levels (10th-90th quantiles). It can be seen that the effect of each determinant varies quite unsystematically in both magnitude and direction across quantiles. The influence of EXP, MAR, and POORINC on household debt was low at the lower quantile levels, then became high along the medium household debt regime before declining in the high debt regime. Meanwhile, GPP, EMPL, and BRA can impart a strong impact on household debt in the North particularly of household in the lower quantiles. Both INCOME and EDU were found to have an ill-defined relationship with household debt as their effects differed unsystematically in magnitude and direction across quantiles.

Table 8. Coefficient estimates from the panel quantile regression model for the Northern Region.

\begin{tabular}{|c|c|c|c|c|c|c|c|c|c|}
\hline \multirow{3}{*}{ Determinant } & \multicolumn{9}{|c|}{ Quantile } \\
\hline & \multicolumn{3}{|c|}{ Low Debt Regime } & \multicolumn{3}{|c|}{ Medium Debt Regime } & \multicolumn{3}{|c|}{ Low Debt Regime } \\
\hline & 10th & 20th & 10th & 40th & 10th & 60th & 10th & 80th & 10th \\
\hline \multirow{2}{*}{ Constant } & -0.566 & -0.481 & -3.164 & -3.121 & -4.315 & -0.829 & -3.340 & -2.270 & 0.093 \\
\hline & (3.501) & (3.729) & (3.444) & (3.41) & (2.901) & (3.043) & (3.136) & (2.691) & $(2.451)$ \\
\hline \multirow{2}{*}{ EXP } & $2.505^{* *}$ & $2.730 * * *$ & $2.861^{* * *}$ & $2.890^{* * *}$ & $2.692 * * *$ & $2.208^{* *}$ & $2.514^{* * *}$ & $2.916^{* * *}$ & 1.614 \\
\hline & (1.134) & (0.963) & (0.789) & $(0.756)$ & $(0.607)$ & (0.709) & (0.837) & (0.969) & $(0.97)$ \\
\hline \multirow{2}{*}{ MAR } & 0.215 & 0.300 & $-0.431^{* *}$ & $0.420 * *$ & 0.276 & 0.175 & 0.030 & -0.052 & -0.237 \\
\hline & $(0.27)$ & $(0.228)$ & (0.177) & $(0.180)$ & (0.207) & $(0.180)$ & $(0.227)$ & $(0.234)$ & (0.247) \\
\hline \multirow{2}{*}{ POORINC } & 0.196 & 0.206 & $0.441^{* *}$ & $0.462 * *$ & $0.441^{* *}$ & 0.279 & 0.356 & 0.338 & 0.147 \\
\hline & $(0.257)$ & $(0.248)$ & $(0.204)$ & $(0.231)$ & $(0.205)$ & $(0.200)$ & $(0.204)$ & $(0.225)$ & $(0.231)$ \\
\hline \multirow{2}{*}{ INCOME } & -0.168 & -0.365 & -0.095 & -0.181 & 0.061 & -0.024 & -0.034 & -0.781 & -0.276 \\
\hline & (1.028) & (0.889) & $(0.784)$ & $(0.701)$ & $(0.667)$ & $(0.688)$ & $(0.727)$ & $(0.786)$ & $(0.740)$ \\
\hline \multirow{2}{*}{ GPP } & $-0.425^{*}$ & $-0.408^{*}$ & $-0.274^{*}$ & -0.259 & -0.333 & -0.295 & -0.296 & -0.183 & -0.096 \\
\hline & $(0.228)$ & (0.194) & $(0.192)$ & $(0.233)$ & $(0.238)$ & $(0.227)$ & $(0.231)$ & $(0.243)$ & $(0.280)$ \\
\hline \multirow{2}{*}{ EDU } & 0.726 & 0.509 & 0.701 & 0.839 & 0.720 & 0.401 & -0.251 & 0.218 & 0.492 \\
\hline & $(0.854)$ & $(0.87)$ & $(0.733)$ & $(0.774)$ & $(0.783)$ & $(0.8)$ & (1.029) & $(0.973)$ & (1.042) \\
\hline \multirow{2}{*}{ EMPL } & -1.738 & $-2.891^{* * *}$ & $-2.163 *$ & $-2.157^{* *}$ & -1.124 & -1.395 & -0.236 & -0.425 & 0.100 \\
\hline & $(1.261)$ & (1.178) & (1.161) & (1.353) & (1.209) & $(1.244)$ & (1.387) & $(1.255)$ & (1.198) \\
\hline \multirow{2}{*}{ BRA } & $-0.473^{* *}$ & $-0.538^{* * *}$ & $-0.553^{* * *}$ & $-0.550^{* * *}$ & $-0.452 * *$ & $-0.409 * *$ & -0.208 & -0.072 & 0.040 \\
\hline & $(0.174)$ & $(0.18)$ & (0.162) & (0.188) & (0.193) & (0.195) & $(0.218)$ & $(0.216)$ & (0.209) \\
\hline
\end{tabular}

$* * *, * * *$ indicate the statistical significance at the $1 \%, 5 \%$ and $10 \%$, respectively and the value in () is the standard error.

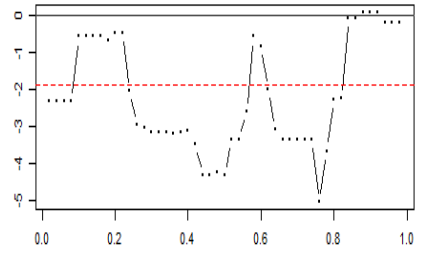

(a)

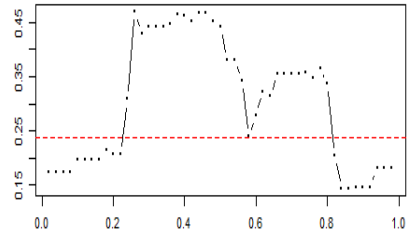

(d)

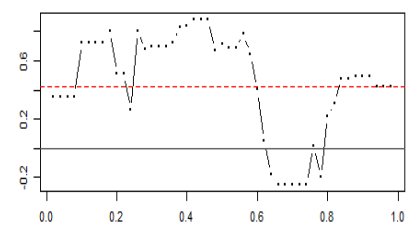

(g)

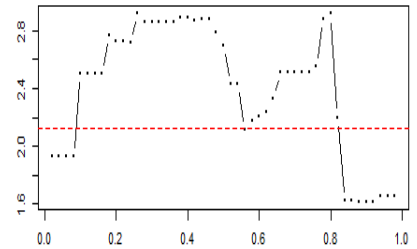

(b)

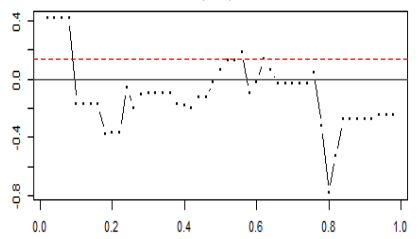

(e)

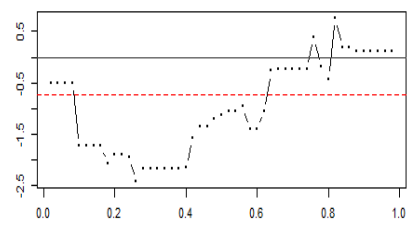

(h)

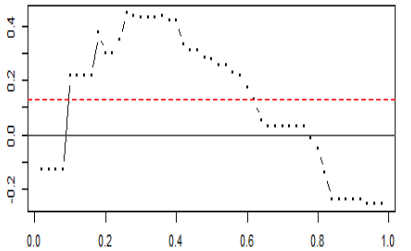

(c)

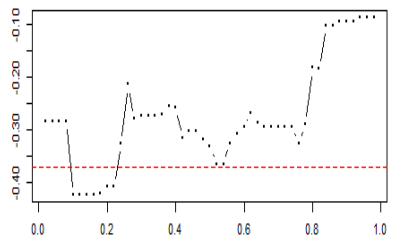

(f)

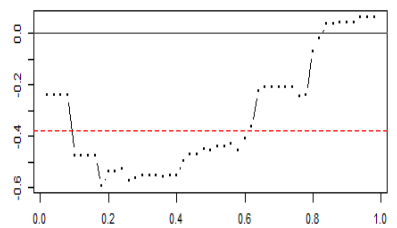

(i)

Figure 5. Coefficient values of each determinant of household debt at different quantile levels (10th-90th), Northern Region. (a) Constant. (b) EXP. (c) MAR. (d) POORINC. (e) INC (f) GPP. (g) EDU. (h) EMPL. (i) BRA. 


\subsubsection{Household Debt Analysis for the Southern Region}

The findings presented in Table 9 reveal the most significant determinant of household debt in the South to be EXP, with influence on household debt at all quantile levels, followed by EMPL. GPP was found to have a small inverse effect on household debt in the low household debt regime. A $1 \%$ change in household expenditure caused household debt to change in the same direction by $2.125-2.535 \%, 2.095-2.783 \%$, and $1.509-2.057 \%$ in the low, the medium, and the high household debt regimes, respectively. The factor of the proportion of active population employed, however, is the significant determinant of Thai household debt in the South and the North only. Its effect was found to differ between these two regions.

Table 9. Coefficient estimates from the panel quantile regression model for the Southern Region.

\begin{tabular}{|c|c|c|c|c|c|c|c|c|c|}
\hline \multirow{3}{*}{ Determinant } & \multicolumn{9}{|c|}{ Quantile } \\
\hline & \multicolumn{3}{|c|}{ Low Debt Regime } & \multicolumn{3}{|c|}{ Medium Debt Regime } & \multicolumn{3}{|c|}{ Low Debt Regime } \\
\hline & 10th & 20th & 10th & 40th & 10th & 60 th & 10th & 80th & 10th \\
\hline Constant & $\begin{array}{c}-8.036^{* *} \\
(3.821)\end{array}$ & $\begin{array}{c}-12.375^{* * *} \\
(3.461)\end{array}$ & $\begin{array}{c}-9.913 * * * \\
(2.940)\end{array}$ & $\begin{array}{c}-9.92 * * * \\
(2.894)\end{array}$ & $\begin{array}{c}-8.976 * * * \\
(3.481)\end{array}$ & $\begin{array}{c}-8.49 * * * \\
(3.251)\end{array}$ & $\begin{array}{c}-11.30 * * * \\
(3.519)\end{array}$ & $\begin{array}{c}-12.08^{* * *} \\
(3.820)\end{array}$ & $\begin{array}{c}-10.00 \text { ** } \\
(4.034)\end{array}$ \\
\hline EXP & $\begin{array}{c}2.125^{* * *} \\
(0.730)\end{array}$ & $\begin{array}{c}2.535 * * * \\
(0.794)\end{array}$ & $\begin{array}{c}2.478^{* * *} \\
(0.750)\end{array}$ & $\begin{array}{c}2.361^{* * *} \\
(0.695)\end{array}$ & $\begin{array}{c}2.783 * * * \\
(0.714)\end{array}$ & $\begin{array}{c}2.095 * * \\
(0.801)\end{array}$ & $\begin{array}{c}1.929 * * * \\
(0.777)\end{array}$ & $\begin{array}{c}2.057^{* * *} \\
(0.699)\end{array}$ & $\begin{array}{c}1.509 \text { ** } \\
(0.73)\end{array}$ \\
\hline MAR & $\begin{array}{c}-0.333 \\
(0.274)\end{array}$ & $\begin{array}{l}-0.100 \\
(0.240)\end{array}$ & $\begin{array}{c}0.060 \\
(0.195)\end{array}$ & $\begin{array}{c}0.070 \\
(0.190)\end{array}$ & $\begin{array}{c}0.099 \\
(0.185)\end{array}$ & $\begin{array}{c}0.069 \\
(0.202)\end{array}$ & $\begin{array}{c}0.020 \\
(0.214)\end{array}$ & $\begin{array}{c}0.018 \\
(0.189)\end{array}$ & $\begin{array}{c}0.114 \\
(0.187)\end{array}$ \\
\hline POORINC & $\begin{array}{l}-0.023 \\
(0.173)\end{array}$ & $\begin{array}{c}-0.161 \\
(0.18)\end{array}$ & $\begin{array}{c}0.142 \\
(0.162)\end{array}$ & $\begin{array}{c}0.154 \\
(0.135)\end{array}$ & $\begin{array}{c}0.138 \\
(0.122)\end{array}$ & $\begin{array}{c}0.070 \\
(0.111)\end{array}$ & $\begin{array}{c}0.148 \\
(0.109)\end{array}$ & $\begin{array}{c}0.124 \\
(0.098)\end{array}$ & $\begin{array}{c}0.172 \\
(0.108)\end{array}$ \\
\hline INCOME & $\begin{array}{c}0.112 \\
(0.607)\end{array}$ & $\begin{array}{l}-0.089 \\
(0.629)\end{array}$ & $\begin{array}{l}-0.285 \\
(0.609)\end{array}$ & $\begin{array}{l}-0.321 \\
(0.504)\end{array}$ & $\begin{array}{c}-0.504 \\
(0.562)\end{array}$ & $\begin{array}{c}0.080 \\
(0.617)\end{array}$ & $\begin{array}{c}-0.142 \\
(0.667)\end{array}$ & $\begin{array}{c}-0.144 \\
(0.638)\end{array}$ & $\begin{array}{c}0.344 \\
(0.638)\end{array}$ \\
\hline GPP & $\begin{array}{c}-0.758 \text { * } \\
(0.433)\end{array}$ & $\begin{array}{l}-0.270 \\
(0.454)\end{array}$ & $\begin{array}{c}-0.214 \\
(0.359)\end{array}$ & $\begin{array}{l}-0.102 \\
(0.366)\end{array}$ & $\begin{array}{l}-0.116 \\
(0.374)\end{array}$ & $\begin{array}{l}-0.291 \\
(0.363)\end{array}$ & $\begin{array}{c}0.189 \\
(0.347)\end{array}$ & $\begin{array}{c}-0.024 \\
(0.337)\end{array}$ & $\begin{array}{c}0.260 \\
(0.322)\end{array}$ \\
\hline EDU & $\begin{array}{c}0.791 \\
(1.272)\end{array}$ & $\begin{array}{c}0.374 \\
(1.341)\end{array}$ & $\begin{array}{c}-0.214 \\
(0.359)\end{array}$ & $\begin{array}{c}-0.101 \\
(0.997)\end{array}$ & $\begin{array}{c}0.467 \\
(0.965)\end{array}$ & $\begin{array}{c}0.262 \\
(1.072)\end{array}$ & $\begin{array}{c}0.783 \\
(1.0512)\end{array}$ & $\begin{array}{l}1.209 \\
(1.03)\end{array}$ & $\begin{array}{c}1.162 \\
(1.279)\end{array}$ \\
\hline EMPL & $\begin{array}{l}3.926 * \\
(2.108)\end{array}$ & $\begin{array}{l}4.293 * * \\
(1.810)\end{array}$ & $\begin{array}{l}3.419 * * \\
(1.678)\end{array}$ & $\begin{array}{l}3.535^{* *} \\
(1.476)\end{array}$ & $\begin{array}{c}2.218 \\
(1.549)\end{array}$ & $\begin{array}{c}2.851 * * \\
(1.349)\end{array}$ & $\begin{array}{c}3.768 * * \\
(1.466)\end{array}$ & $\begin{array}{c}4.330 * * \\
(1.711)\end{array}$ & $\begin{array}{c}2.431 \\
(1.978)\end{array}$ \\
\hline BRA & $\begin{array}{c}0.326 \\
(0.221)\end{array}$ & $\begin{array}{c}0.129 \\
(0.219)\end{array}$ & $\begin{array}{c}-0.039 \\
(0.173)\end{array}$ & $\begin{array}{c}-0.050 \\
(0.173)\end{array}$ & $\begin{array}{c}-0.062 \\
(0.182)\end{array}$ & $\begin{array}{c}-0.056 \\
(0.172)\end{array}$ & $\begin{array}{c}-0.071 \\
(0.186)\end{array}$ & $\begin{array}{c}-0.154 \\
(0.16)\end{array}$ & $\begin{array}{c}-0.219 \\
(0.156)\end{array}$ \\
\hline
\end{tabular}

$* * * * * *$ indicate the statistical significance at the $1 \%, 5 \%$ and $10 \%$, respectively and the value in () is the standard error.

A 1\% increase in EMPL in the North reduced at a statistical significance level the household debt in the low and the medium household debt regimes (20th to 40th quantiles); while in the South, it caused household debt to increase in almost all household debt regimes. The positive relationship between household debt and employment in the South probably comes from the employment stability and greater income security of these households, which affords them better access to credit. Such a relationship may also come from the fact that people in the South are engaged primarily in farming and fishery occupations, and the rise in employed persons can increase the need for borrowing for productive investment in the agricultural and fishery sectors.

The results presented in Table 9 can be shown graphically as in Figure 6 to illustrate the varying effect of each determinant of household debt at different quantile levels (10th-90th quantiles). Evidently, similarly to the North, the effects of EXP and POORINC in the South were low when household debts were in the low regime, and then became stronger in the medium debt regime, before weakening again in the high debt regime. INC, or household income, was highly influential for household debts in the low debt regime, but its effect was lower in the medium debt regime before becoming high again in the high debt regime. Meanwhile, the effects of EMPL and BRA tended to weaken while those of MAR, GPP, and EDU tended to strengthen as the quantile level of household debt rose. 


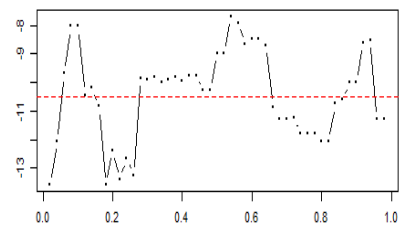

(a)

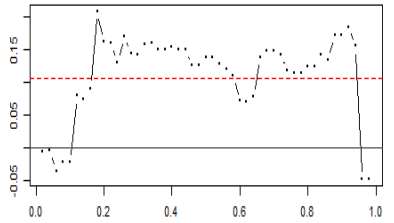

(d)

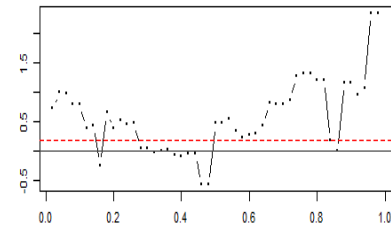

(g)

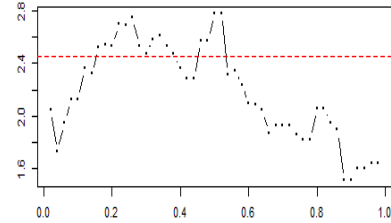

(b)

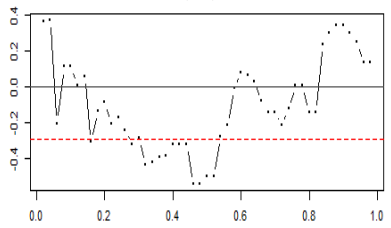

(e)

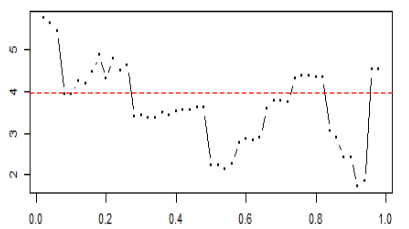

(h)

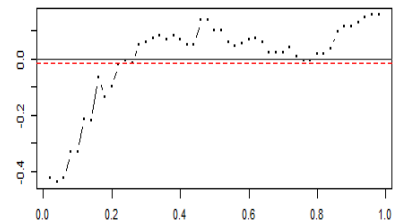

(c)

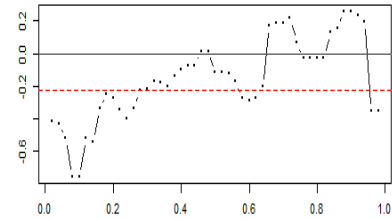

(f)

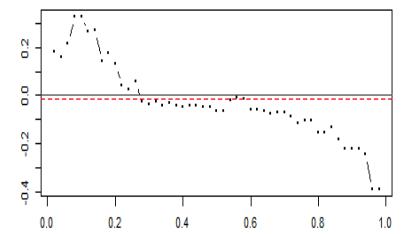

(i)

Figure 6. Coefficient values of each determinant of household debt at different quantile levels (10th-90th), Southern Region. (a) Constant. (b) EXP. (c) MAR. (d) POORINC. (e) INC (f) GPP. (g) EDU. (h) EMPL. (i) BRA.

As for the Western Region, the PQR model estimation provided coefficients that were not statistically significant for any household debt determinants, and thus these findings are not reported in this article. The non-statistically significant regression results can be partly explained by the limitations of the small sample and the limited length of time-series data available for analyzing the Western Region. Such econometric problems will lead to biased and non-statistically significant estimates, which are not reliable for analysis and forecasting.

4.4. Testing the Equality of the Estimated Quantile Regression Coefficients across Household Debt Regimes

The Wald-test was conducted to test the equality of the estimated coefficients with the null hypothesis that the effects of the explanatory variables on all household debt regimes of interest are not different. The test results are presented in Table 10.

Table 10. $p$-values of Wald tests.

\begin{tabular}{|c|c|c|c|c|c|c|c|c|}
\hline Determinant & Quantile & $\begin{array}{l}\text { Whole } \\
\text { Country }\end{array}$ & North & Central & South & East & Northeast & West \\
\hline \multirow[t]{3}{*}{ EXP } & 20 th vs. 50 th & 0.3399 & 0.4867 & 0.8616 & 0.5918 & 0.4897 & 0.6089 & 0.5758 \\
\hline & 20th vs. 80 th & $0.0042^{* * *}$ & 0.5541 & 0.8558 & $0.001^{* * *}$ & 0.5883 & 0.7557 & 0.5430 \\
\hline & 50th vs. 80 th & 0.3935 & 0.5777 & 0.4340 & 0.2337 & 0.6007 & 0.6523 & 0.4764 \\
\hline \multirow[t]{3}{*}{ MAR } & 20 th vs. 50 th & $0.0403^{* *}$ & 0.4689 & 0.2026 & 0.7443 & 0.5587 & 0.3105 & 0.0975 * \\
\hline & 20 th vs. 80 th & $0.0019^{* * *}$ & 0.0944 * & $0.0061^{* * *}$ & 0.6504 & 0.5069 & 0.3341 & 0.0683 * \\
\hline & 50th vs. 80 th & 0.0707 * & 0.1000 * & $0.0415^{* *}$ & 0.3797 & 0.4298 & 0.5163 & 0.3344 \\
\hline \multirow[t]{3}{*}{ POORINC } & 20 th vs. 50 th & 0.3112 & 0.7674 & 0.5470 & 0.9154 & 0.3092 & 0.1789 & 0.7148 \\
\hline & 20th vs. 80th & 0.3076 & 0.6533 & 0.6509 & 0.9178 & 0.6824 & 0.1257 & 0.7541 \\
\hline & 50th vs. 80 th & 0.4819 & 0.3675 & 0.6269 & 0.4644 & 0.8397 & 0.3947 & 0.5793 \\
\hline \multirow[t]{3}{*}{ INC } & 20th vs. 50 th & 0.0941 * & 0.6493 & $0.0756^{*}$ & 0.3114 & 0.6113 & 0.3083 & 0.3688 \\
\hline & 20th vs. 80 th & 0.0540 * & 0.3630 & 0.0100 * & 0.4755 & 0.6700 & 0.0091 * & 0.2428 \\
\hline & 50th vs. 80th & $0.0115^{* *}$ & 0.2070 & 0.3762 & 0.6640 & 0.5665 & 0.2466 & 0.3416 \\
\hline \multirow[t]{3}{*}{ GPP } & 20th vs. 50 th & 0.9903 & 0.9921 & 0.1729 & 0.6033 & 0.4745 & 0.2825 & 0.6153 \\
\hline & 20th vs. 80 th & 0.9984 & 0.7653 & 0.5546 & 0.6682 & 0.5891 & 0.4630 & 0.7095 \\
\hline & 50th vs. 80 th & 0.7579 & 0.6704 & 0.9035 & 0.5725 & 0.6239 & 0.6676 & 0.6150 \\
\hline \multirow[t]{3}{*}{ EDU } & 20th vs. 50th & 0.5736 & 0.5715 & $0.1000 *$ & 0.5224 & 0.2740 & 0.6327 & 0.6151 \\
\hline & 20th vs. 80th & $0.0031^{* * *}$ & 0.4118 & 0.3582 & 0.6893 & 0.3322 & 0.7774 & 0.5207 \\
\hline & 50th vs. 80 th & $0.0051^{* * *}$ & 0.3439 & 0.7383 & 0.7005 & 0.5746 & 0.6982 & 0.3953 \\
\hline
\end{tabular}


Table 10. Cont.

\begin{tabular}{clccccccc}
\hline \multirow{2}{*}{ Determinant } & Quantile & $\begin{array}{c}\text { Whole } \\
\text { Country }\end{array}$ & North & Central & South & East & Northeast & West \\
\hline \multirow{2}{*}{ EMPL } & 20th vs. 50th & $0.0107^{* *}$ & 0.6752 & 0.9155 & 0.1919 & 0.1300 & 0.5619 & 0.6429 \\
& 20th vs. 80th & $0.0499 * *$ & 0.8028 & 0.9458 & 0.5059 & 0.1185 & 0.5364 & 0.6785 \\
\multirow{2}{*}{ BRA } & 50th vs. 80th & 0.6842 & 0.6558 & 0.5793 & 0.8199 & 0.4974 & 0.4643 & 0.5449 \\
& 20th vs. 50th & 0.8617 & 0.6277 & 0.8681 & 0.2512 & 0.3344 & 0.6648 & 0.5540 \\
& 20th vs. 80th & 0.9849 & 0.9513 & 0.9904 & 0.1484 & 0.4789 & 0.7178 & 0.6040 \\
& 50th vs. 80th & 0.8943 & 0.9052 & 0.8833 & 0.3521 & 0.6757 & 0.5756 & 0.5670 \\
\hline
\end{tabular}

Note $* * * * *, *$ indicate the statistical significance at the $1 \%, 5 \%$, and $10 \%$, respectively.

Table 10 shows the pair-wise comparison of the effect of each explanatory variable on the dependent variable between two different household debt regimes: specifically, 20th vs. 50 th, 20th vs. 80 th, and 50th vs. 80th quantiles. At the whole-country level, virtually all household debt determinants-except GPP, POORINC, and BRA - differ in terms of their influence on the household debt in different debt regimes. In other words, a particular determinant has differential effects on different household debt regimes, and this finding confirms that the Panel Quantile Regression is a suitable model for estimating time-series with non-normal distribution function. At the regional level, however, the null hypothesis was rejected for only a few explanatory variables, suggesting that most determinants exerted quite similar effects across regions and household debt regimes. The similar demographic characteristics and borrowing behaviors of Thai people up-country may be a reason for various household debt determinants having comparable effects on household borrowing in all household debt regimes.

\subsection{Beta Convergence and Sigma Convergence}

The last part of this study is devoted to determining whether household debt convergence exists in Thailand at both the national and the regional levels. The concept of economic convergence is applied to assess if household debt levels will eventually be similar everywhere, and to reflect on whether all segments of the Thai population have equal access to credit sources. The findings on Beta convergence and Sigma convergence are reported in Tables 11 and 12 respectively.

Table 11. Beta $(\beta)$ convergence results.

\begin{tabular}{cccc}
\hline Region & $\beta$ & $p$-Value & Convergence \\
\hline Central & 0.0944 & $0.0000^{* * *}$ & Divergence \\
East & 0.2186 & $0.0090^{* * *}$ & Divergence \\
Northeast & 0.0597 & 0.2160 & - \\
North & 0.0294 & 0.6500 & - \\
South & 0.0739 & $0.0022^{* *}$ & Divergence \\
West & 0.1494 & 0.3460 & - \\
Whole country & 0.1399 & $0.0000^{* *}$ & Divergence \\
\hline
\end{tabular}

**,*** indicate the statistical significance at the $5 \%$, and $1 \%$, respectively.

Table 12. Sigma $\left(\sigma^{2}\right)$ convergence results.

\begin{tabular}{ccccc}
\hline Region & $\sigma^{2} \mathbf{2 0 0 8}$ & $\sigma^{2} \mathbf{2 0 1 7}$ & $p$-Value & Convergence \\
\hline Central & 0.1105 & 0.2428 & $0.0007 * * *$ & Divergence \\
East & 0.2545 & 0.3206 & 0.5888 & - \\
Northeast & 0.2425 & 0.3045 & 0.3426 & - \\
North & 0.4728 & 0.5642 & 0.6286 & - \\
South & 0.6991 & 0.6800 & 0.9217 & - \\
West & 0.3222 & 0.2619 & 0.6979 & - \\
Whole country & 0.4966 & 0.5046 & 0.8907 & - \\
\hline
\end{tabular}

*** indicates the statistical significance at the $1 \%$. 


\subsubsection{Beta Convergence}

The results shown in Table 11 reveal $\beta$ coefficients to be positive for all the six regions, including for the whole country, indicating the non-existence of household debt convergence across the board. To be specific, during the study period, household debt levels of various households within a given region as well as within a given province did not change toward reaching a similar level. This tendency clearly reflects the different borrowing and loan repayment behaviors among different population groups that might give rise to greater household debt differences across households and geographic regions, particularly for the Central, Eastern, and Southern Regions. Meanwhile, the statistically significant positive $\beta$ for the whole country implies the existence of regional household debt divergence.

\subsubsection{Sigma Convergence}

The results of the Sigma convergence test for each of the six regions and the whole country were examined to confirm the results obtained from the Beta convergence. The results of the Sigma convergence test are displayed in Table 11. Only the Central Region was found to have significant Sigma divergence. The Sigma divergence indicated a growing dispersion of household debt levels among different households over time, which is likely to occur in the Central Region where the capital city is located. Bangkok, the capital and the most populous city of the country, on one hand has been the top choice of migration destinations of a large number of rural people seeking a higher income, due to the vast levels of employment opportunity in many industries and service sectors. Most rural migrants are unskilled labor and are poorly educated, able only to make low incomes and live in poverty in slums. On the other hand, Bangkok is also home to the well-educated, the middle-class, and the young families with different financial backgrounds, social statuses, and job opportunities. Thus, the factors of differential income and lifestyle among different groups of people alone may be enough to explain the diverse borrowing behaviors and household debt divergence of households in Bangkok and the Central Region.

\section{Conclusions and Recommendations}

Household debt in Thailand is a problem of national concern requiring close surveillance and holistic study, because over-indebtedness and its persistence may harm people's quality of life, the country's economic growth and development, and national financial stability. In recognition of the significance of Thai household debt issues, we undertook this study to analyze the determinants and impacts of household debts for comparison across household groups and regions in Thailand. Consequently, the Panel Quantile Regression model was employed using the panel data of 76 provinces for analysis at the national and regional levels, and across three household debt regimes, namely, the low (10th, 20th, and 30th quantiles), the medium (40th, 50th, and 60th quantiles), and the high (70th, 80th, and 90th quantiles) household debt regimes. For the national level, the results at the statistical significance level reveal that an increase in household expenditure and household income led to an increase in household debt in all household debt regimes, and economic growth (GDP per capita) helped reduce household debt at all quantile levels. It was observed that all the results were in the directions supporting the null hypotheses, except for the household income variable, which was found to have a positive association with household debt, as the higher household income led to a higher level of borrowing. The findings of our study are consistent with those of Lerskullawat [10], Baker [15], and Keese [16]. Meanwhile, an increased number of registered marriages was found to increase household debt only in those households in the low and the medium debt regimes. This result is in line with Lea, Webley and Walker [17], DeVaney and Lytton [37], and Wildauer [18]. Similarly, the number of commercial bank branches had an effect on the debt of the households in the low and the medium debt regimes only. As the number of commercial bank branches is used to present credit-accessibility characteristics, the higher the credit-accessibility of household, the higher the level of indebtedness [14]. 
For the regional level, this study found that an increase in household expenditure caused household debt to increase in virtually all regions of the country. The next most dominant determinant was found to be the number of registered marriages, which had a varying degree of impact on households in different household debt regimes and different geographic regions. Meanwhile, a growing number of commercial bank branches of resulted in a reduction in household debt. A possible explanation for this relationship is that certain households, which had previously borrowed from informal lenders at high interest rates, were then able to access low-interest loans after the opening of new commercial branches, thus also accessing loan-use and debt-management guidelines from experienced financial advisors at the bank, which enabled them to reduce household debt. The last determinant, the GPP per capita or the macroeconomic variable, could help reduce household debt with its expansion; but it had a favorable effect only on the Central and the Eastern Regions. As these two regions are the country's major business and industrial centers with a large economies, their economic expansion can easily help households in all household debt regimes to reduce indebtedness levels. It should also be noted that the findings on these two regions and on the whole country are similar; therefore, any policy and program formulated and implemented by the Bank of Thailand and the government to deal with household debt problems are likely to benefit the households in the Central and Eastern Regions more than the rest.

The tests of the equality of quantile regression coefficients reveal that, at the national level, various determinants had different effects on households in the three different household debt regimes. Conversely, the effects of various determinants at the regional level were found to be quite similar across the three household debt regimes, although there were significant differences among geographic regions as well as within each region, in many aspects. This means that the design and implementation of a universal policy for maintaining household debt in Thailand at a manageable level, without taking into account the regional differences, would not be effective or realistic. Thus, the finding on this aspect indeed confirms the practicality of using the Panel Quantile Regression model for the analysis.

Finally, the convergence tests revealed the non-existence of household debt convergence in Thailand at both the national and the regional levels. On the contrary, statistically significant household debt divergence was found to exist in some geographic regions, indicating a growing difference in household debt levels across regimes, probably due to the unequal access to financial resources among different households in Thai society.

In a nutshell, the results of this study demonstrate that although each household debt determinant has remarkably different effects on household borrowing in different geographic regions in both magnitude and direction, likewise, household borrowing behavior also varies across households within each region. Furthermore, the finding of the non-existence of household debt convergence in Thailand confirms the theory that policies to solve household debt problems should be designed as region-specific protocols to ensure more effective implementation.

\section{Policy Recommendations}

1. The analysis of household debt determinants in this study revealed that household expenditure and household income, when increased, led to a higher household debt level. This empirical finding contradicts the general assumption that household debt is reduced with increased household expenditure due to the household becoming more careful about borrowing more money, as well as the increased household income helping enhance loan repayment ability. However, the present finding may reflect the possibility that some Thai households are financially illiterate and lack an understanding of financial planning. Therefore, the development of financial knowledge and discipline in every Thai person is highly imperative, not only among the indebted households. 
2. The results from testing the equality of regression coefficients indicate various household debt determinants had varying degrees of impact on the whole country and across regions, except for the Central and Eastern Regions, which share similar features with the national level particularly the factor of economic development. The GPP growth resulted in a significant reduction in household debt at all household debt quantiles and regimes in the Central and the Eastern Regions, which are the center of economic activities of the country. As the macroeconomic determinant can bring about a direct positive impact for households, the policy of establishing an economic zone in every region of Thailand is necessary for systematic reduction in household debt nationwide following sustainable economic development.

3. The test for household debt convergence in Thailand revealed, instead, the existence of household debt divergence at the statistical significance level, suggesting extremely different household borrowing behaviors across regions. Hence, the use of a universal policy, or the one-size-fits-all concept for every region, may not be appropriate. The government and the Bank of Thailand should launch region-specific policies to solve household debt problems in each region with an adequate understanding of the mechanisms behind the situations in the particular region. An example of the region-specific features found from this study is the fact that the variable of the proportion of population living in poverty is a significant determinant of household debt only in the Northern and the Northeastern Regions. This means the government, or the Bank of Thailand, need not implement the lowering-poverty headcount policy in all regions, which could help save the human and financial resources for more appropriate implementation. Moreover, the finding that, in the Northeast, household debt still rose even as household income increased, suggests it is crucial to give special attention to this region by implementing the lowering-poverty headcount policy and helping the poor to acquire more financial literacy and sustain their consumption in the future.

Author Contributions: Conceptualization, P.M., S.T. and A.R. carried out the literature review, statistical analysis, and drafted the manuscript. S.T. and A.R. helped with the data collections, data analysis, and discussion. P.M. and W.Y. made major contributions to writing the manuscript, and W.Y. prepared the computer code and estimation. All authors have read and agreed to the published version of the manuscript.

Funding: The paper is supported by the Center of Excellence in Econometrics, Faculty of Economics, Chiang Mai University.

Data Availability Statement: The data is obtained from National Statistical Office of Thailand.

Acknowledgments: The authors would like to thank Laxmi Worachai for her constructive comments to improve our paper.

Conflicts of Interest: The authors declare no conflict of interest.

\section{References}

1. Debelle, G. Household debt and the macroeconomy. BIS Q. Rev. 2004, 3, 51-64.

2. Debelle, G. Macroeconomic Implications of Rising Household Debt; BIS Working Papers 153; Bank for International Settlements: Basel, Switzerland, 2004.

3. Koenker, R. Quantile Regression; Cambridge University Press: New York, NY, USA, 2005.

4. Escolano, J. A practical guide to public debt dynamics, fiscal sustainability, and cyclical adjustment of budgetary aggregates. Int. Monet. Fund 2010, 2010, 1-25. [CrossRef]

5. Apergis, N.; Cooray, A. Convergence in sovereign debt ratios across heavily indebted EU countries: Evidence from club convergence. Appl. Econ. Lett. 2014, 21, 786-788. [CrossRef]

6. Akram, V.; Rath, B.N. Does debt convergence hold in case of India? J. Econ. Stud. 2019, 46, 858-871. [CrossRef]

7. Amornlerdphanich, B. Factors Determining Household's Debt in Northern Region of Thailand; Chiang Mai University: Chiang Mai, Thailand, 2008. 
8. Rangsipaht, S.; Thaipakdee, S.; Keosonthi, C.; Saengchan, N.; Parnuwad, K. Reasons of being in debts and their solutions for career preparation of graduate students in agricultural extension. In Proceedings of the 51st Kasetsart University Annual Conference, Bangkok, Thailand, 5-7 February 2013; Kasetsart University: Bangkok, Thailand, 2013.

9. Chichaibelu, B.B.; Waibel, H. Over-indebtedness and its persistence in rural households in Thailand and Vietnam. J. Asian Econ. 2018, 56, 1-23. [CrossRef]

10. Lerskullawat, A. Factors affecting household debt in Thailand. Int. J. Econ. Policy Emerg. Econ. 2020, 13, 327.

11. Chotewattanakul, P.; Sharpe, K.; Chand, S. The Drivers of Household Indebtedness: Evidence from Thailand. Southeast Asian J. Econ. 2019, 7, 1-40.

12. Ho, C.S.; Mainal, S.A. Household Indebtedness Determinants in ASEAN Developing Countries. J. Wealth Manag. Financ. Plan. 2016, 3, 46-60.

13. Kotze, L. Debt and the Management of Personal Finances. Ph.D. Thesis, University of the Free State, Bloemfontein, South Africa, 2006.

14. Muthitacharoen, A.; Nuntramas, P.; Chotewattanakul, P. Rising household debt: Implications for economic stability. Thail. World Econ. 2015, 33, 43-65.

15. Baker, S.R. Debt and the response to household income shocks: Validation and application of linked financial account data. J. Political Econ. 2018, 126, 1504-1557. [CrossRef]

16. Keese, M. Who feels constrained by high debt burdens? Subjective vs. objective measures of household debt. J. Econ. Psychol. 2012, 33, 125-141. [CrossRef]

17. Lea, S.E.; Webley, P.; Walker, C.M. Psychological factors in consumer debt: Money management, economic socialization, and credit use. J. Econ. Psychol. 1995, 16, 681-701. [CrossRef]

18. Wildauer, R. Determinants of US Household Debt: New Evidence from the Scf. Economics Discussion Papers 2016-6; Kingston University London: London, UK, 2016.

19. Crawford, A.; Faruqui, U. What explains trends in household debt in Canada? Bank Can. Rev. 2011, $2011,3-15$.

20. Rahman, M.; Azma, N.; Masud, M.; Kaium, A.; Ismail, Y. Determinants of indebtedness: Influence of behavioral and demographic factors. Int. J. Financ. Stud. 2020, 8, 8. [CrossRef]

21. Son, J.C.; Park, H. US Interest Rate and Household Debt Sustainability: The Case of Korea. Sustainability 2019, 11, 3759. [CrossRef]

22. Mian, A.; Sufi, A.; Verner, E. Household debt and business cycles worldwide. Q. J. Econ. 2017, 132, 1755-1817. [CrossRef]

23. Meniago, C.; Mukuddem-Petersen, J.; Petersen, M.A.; Mongale, I.P. What causes household debt to increase in South Africa? Econ. Model. 2013, 33, 482-492. [CrossRef]

24. Meng, X.; Hoang, N.T.; Siriwardana, M. The determinants of Australian household debt: A macro level study. J. Asian Econ. 2013, 29, 80-90. [CrossRef]

25. Abd Samad, K.; Mohd Daud, S.N.; Mohd Dali, N.R.S. Determinants of household debt in emerging economies: A macro panel analysis. Cogent Bus. Manag. 2020, 7, 1831765. [CrossRef]

26. Zhu, H.; Duan, L.; Guo, Y.; Yu, K. The effects of FDI, economic growth and energy consumption on carbon emissions in ASEAN-5: Evidence from panel quantile regression. Econ. Model. 2016, 58, 237-248. [CrossRef]

27. Garza-Rodriguez, J.; Ayala-Diaz, G.A.; Coronado-Saucedo, G.G.; Garza-Garza, E.G.; Ovando-Martinez, O. Determinants of Poverty in Mexico: A Quantile Regression Analysis. Economies 2021, 9, 60. [CrossRef]

28. Koenker, R. Quantile regression for longitudinal data. J. Multivar. Anal. 2004, 91, 74-89. [CrossRef]

29. Alexander, M.; Harding, M.; Lamarche, C. Quantile regression for time-series-cross-section data. Int. J. Stat. Manag. Syst. 2011, 6, 47-72.

30. Koenker, R.; Bassett, G., Jr. Robust tests for heteroscedasticity based on regression quantiles. Econom. J. Econom. Soc. 1982, 50, 43-61. [CrossRef]

31. Furceri, D. $\beta$ and $\sigma$-convergence: A mathematical relation of causality. Econ. Lett. 2005, 89, 212-215. [CrossRef]

32. Young, A.T.; Higgins, M.J.; Levy, D. Sigma convergence versus beta convergence: Evidence from US county-level data. J. Money Credit. Bank. 2008, 40, 1083-1093. [CrossRef]

33. Baumol, W.J. Productivity growth, convergence, and welfare: What the long-run data show. Am. Econ. Rev. 1986, 76, 1072-1085.

34. Barro, R.J.; Sala-i-Martin, X. Convergence. J. Political Econ. 1992, 100, 223-251. [CrossRef]

35. Mankiw, N.G.; Romer, D.; Weil, D.N. A contribution to the empirics of economic growth. Q. J. Econ. 1992, 107, 407-437. [CrossRef]

36. Jarco, D. Testing and measurement of economic convergence: A review of some recent developments. Int. Entrep. Przedsibiorczosć Miedzynar. 2018, 4, 9-29. [CrossRef]

37. DeVaney, S.A.; Lytton, R.H. Household insolvency: A review of household debt repayment, delinquency, and bankruptcy. Financ. Serv. Rev. 1995, 4, 137-156. [CrossRef] 